\title{
Institucionalização do sistema partidário ou evolução da competição? \\ Uma proposta de interpretação econômica da volatilidade eleitoral
}

\begin{tabular}{c}
\hline Paulo Sergio Peres \\
Departamento de Ciência Política \\
Universidade Federal do Rio Grande do Sul \\
\hline \hline
\end{tabular}

\begin{abstract}
Resumo: Este artigo tem dois objetivos correlacionados: em primeiro lugar, discutir as anomalias lógicas, conceituais e empíricas das interpretações canônicas do índice de volatilidade eleitoral, entendido como mediador empírico do grau de institucionalização dos sistemas partidários, e, em segundo lugar, propor uma interpretação alternativa para o índice, abandonando-se o viés sociológico em favor de uma abordagem econômica. Nesse caso, o sistema partidário deve ser concebido como um "mercado eleitoral", no qual o grau de restrições (regras e recursos) tem peso significativo na dinâmica da "oferta" (partidos disponíveis e política oferecidas e/ou executadas) e da "demanda" (eleitores individuais, classes econômicas, grupos étnicos, linguísticos ou religiosos e todo o tipo de clivagens sociais), e a volatilidade eleitoral reflete os movimentos evolutivos desse mercado.
\end{abstract}

Palavras-chave: volatilidade eleitoral; instabilidade eleitoral; sistema partidário; institucionalização

Abstract: This article has two related objectives. Firstly, I shall discuss the logical, conceptual and empirical anomalies of the canonical interpretations, and, secondly, I propose an alternative interpretation for the index, which leaves the sociological bias behind in favor of an economic approach. As pointed out, the economic approach analyses party systems as an "electoral market" in which the degree of constraints (rules and resources) has significant weight in the dynamics of "supply" (available political parties and policies offered and implemented) and "demand" (individual voters, economic classes, ethnic, linguistic or religious grounds and all kinds of social cleavages), and electoral volatility reflects the evolutive movements of the political market.

Keywords: electoral volatility; electoral instability; party systems; institutionalization 


\section{Introdução ${ }^{1}$}

A análise comparada dos sistemas partidários consolidou-se como uma produtiva indústria de elaboração de índices. Considerando apenas as medidas de desproporcionalidade na distribuição de cadeiras legislativas em relação aos votos recebidos pelos partidos e de volatilidade eleitoral, Taagepera e Grofman (2003) mapearam a existência de nada menos do que 19 índices mais utilizados e recomendados pela literatura temática a partir da década de 1960. Não obstante, seguindo de perto levantamentos similares (MONROE, 1994; PenNISI, 1998; CORTONA et al, 1999), os autores fizeram questão de ressaltar que esse total está muito aquém de esgotar a massiva coleção de incontáveis índices e famílias de índices criados desde então. Em realidade, essa proliferação deve-se, principalmente, às tentativas de apreensão empírica da distorção da representação partidária, pois, ao contrário da volatilidade eleitoral, cuja mensuração se consolidou sem grandes controvérsias (cf. Bartolini e Mair, 1990) em torno da fórmula proposta por Pedersen (1979, 1980), a busca pela melhor medida da proporcionalidade da representação tornou-se um sangrento campo de batalha, no qual se defrontaram vários índices concorrentes. Com efeito, depois da publicação do clássico trabalho de Rae (1967), o que ocorreu foi o inverso do esperado para esses casos de aplicação de indicadores quantitativos, ou seja, "(...) instead of converging toward the use of one or a few indices, the field of alternatives has lately expanded at a faster rate than ever" (TAAGEPERA \& GROFMAN, 2003, p. 662).

Em decorrência dessa profusão de fórmulas destinadas à apreensão de fenômenos bastante semelhantes - em essência, a diferença entre dois conjuntos de grandezas ·, Taagepera \& Grofman (2003) resolveram colocar alguma ordem nesse cenário quase caótico de fórmulas. Propuseram nada menos do que 12 critérios para que se pudesse atestar a qualidade, digamos assim, dos índices à medida que satisfizessem, senão a todos, pelo menos a quase todos os itens de sua check-list metodológica ${ }^{2}$. Ao final, constataram que nenhum dos mais reputados índices satisfaz plenamente a todos os critérios sugeridos; apesar de dois deles, os de Gallagher (1991) e de Loosemore \& Hanby (1971), aproximarem-se muito disso, com uma ligeira vantagem para o primeiro. Mas, o mais importante a ser destacado dessa avaliação é que todos os índices escrutinados foram submetidos a uma inspeção estritamente técnica, com base em critérios relacionados com as formas de sua operacionalização empírica e a consistência lógica de suas formulações matemáticas. Em nenhum momento, a análise desse "zoo de índices", conforme a designação dos próprios autores, investiu na consideração dos significados teóricos dessas medidas, ou seja, o que eles realmente podem significar e como interpretá. los.

\footnotetext{
1 Este artigo é o desenvolvimento de uma discussão iniciada na minha tese de Doutorado, defendida no Programa de Pós. Graduação em Ciência Política, da Universidade de São Paulo. Por isso, devo agradecer a Maria Hermínia Tavares de Almeida, Leôncio Martins Rodrigues, Rachel Meneguello, Jairo Nicolau e, especialmente, Fernando Limongi, meu orientador, pelas observações críticas que fizeram àquela altura, as quais espero ter conseguido incorporar na atual versão. Agradeço ainda à FAPESP pelo apoio financeiro que possibilitou a pesquisa inicial desse tema. Registro também meu agradecimento a Yan Carreirão, que leu atentamente a atual versão e chamou minha atenção para a necessidade da retificação de pontos técnicos importantes. Aos pareceristas anônimos de Opinião Pública também devo expressar meus mais sinceros agradecimentos, pois seus comentários e sugestões contribuíram sensivelmente para a melhora do argumento e, portanto, da discussão como um todo. Finalmente, agradeço à Fundação de Amparo à Pesquisa do Estado do Rio Grande do Sul (FAPERGS) pelo apoio financeiro, desde 2011, ao projeto de pesquisa que conduziu ao desenvolvimento da discussão presente neste artigo.

2 Esses critérios sete teóricos e cinco operacionais- abrangem aspectos tais como a necessidade de completude das informações, da uniformidade dos dados para todos os partidos, da simetria de x e y, da variação dos valores entre 0 e 1 , do valor 0 para a perfeita concordância entre os conjuntos de valores $\mathrm{x}$ e y $\cdot$ ou seja, de yi $=\mathrm{xi}$ para todo $\mathrm{i} \cdot$, do valor 1 se yi $=0$ para todo $x i>0$ e xi $=0$, e para todo yi >0, mostrando total discordância entre os conjuntos de dados $x$ e y; e assim por diante.
} 
PERES, P. S. Institucionalização do sistema partidário ou evolução da competição?...

Sem dúvida, checagens desse tipo são importantes, mas, de forma alguma, suficientes para considerarmos teoricamente justificadas as interpretações que se fazem dos resultados alcançados pelo uso dos índices. Seguramente, tais indicadores não foram elaborados apenas para afastar o tédio intelectual de pesquisadores aficionados por números e quebra-cabeças matemáticos, mas, sim, para tornar empiricamente operacionais certos conceitos vinculados a determinadas perspectivas teóricas, as quais, por sua vez, relacionam-se umbilicalmente com certas cosmologias e axiologias, ou, em outras palavras, com elementos lógico-conceituais. Destarte, anteriormente à consistência das premissas e das operações matemáticas de cada índice, existe o propósito de interpretar um fenômeno teoricamente construído que, inclusive, serve de motivação para a elaboração de tais medidas. Isso quer dizer que é igualmente importante a consideração de um segundo procedimento na avaliação crítica desses índices, que consiste na explicitação do problema de fundo que levou à sua formulação, e mais ainda, na consideração dos significados teóricos das medidas encontradas e, portanto, das interpretações possíveis e justificáveis para os resultados numéricos obtidos.

Consideremos, por exemplo, as várias medidas de proporcionalidade da representação. Todas elas têm como motivação teórica o problema da representação política e a preocupação normativa com alguma forma de justiça distributiva. A cosmologia que Ihe dá suporte assenta-se na perspectiva liberal acerca do mundo político, articulando a soberania popular com o princípio da representação e o constitucionalismo. Por consequência, as reflexões teóricas, assim como as questões empíricas, concentram-se no problema da ocupação do quinhão do poder político dividido que cabe ao "povo", o que, por sua vez, demanda, ao mesmo tempo, a representação e a competição pelo direito de representá-lo - alguns diriam que reside aí o elemento aristocrático dos governos representativos (MANIN, 1997), e outros poderão dizer ainda que, por essa fresta conceitual, valida-se o princípio básico da escola elitista (Bottomore, 1964; MACPHERSON, 1977; Held, 1987; CunNingham, 2002). Logo, em termos axiológicos, há que se buscar sobretudo a representação justa, o que nos remete ao problema operacional de como promover a equilibrada distribuição das cadeiras representativas de acordo com a distribuição dos votos que investiram certos indivíduos do direito de a outrem representar. Se é mais justo ou não que se represente a vontade da maioria ou das diversas minorias, na proporção de sua manifestação eleitoral, é algo polêmico que envolve o princípio da representação e configura um debate que está na agenda das querelas acadêmicas desde o século XIX sem qualquer vislumbre de concórdia; por isso, não é o caso de singrarmos esse mar revolto neste momento. Mas, ainda assim, em qualquer um dos casos, permanecem tanto a posição valorativamente favorável à busca da melhor distribuição da representação como também o problema de se estabelecerem os mecanismos práticos para a promoção de tal objetivo; o que nos leva à refrega normativa e às inumeráveis pesquisas comparativas acerca das fórmulas eleitorais, outra odisseia a ser cautelosamente evitada por agora.

Portanto, a preocupação axiológica de mensurar a desproporção da representação em decorrência dos efeitos do sistema eleitoral sobre a alocação de cadeiras representativas, mediante a proporção de votos recebidos pelos candidatos ou partidos, é por si mesma uma preocupação com a justiça distributiva aplicada à arena eleitoral. Como tal, não somente torna explícita a intenção normativa de reivindicar ajustes nas regras que transformam votos em cargos representativos, como também permite uma interpretação teórica inequívoca de qualquer valor extraído do cálculo dos diversos índices 
destinados a esse tipo de mensuração. Não há dúvidas, então, quanto ao que significa algum grau de desproporcionalidade, afinal, qualquer um dos indicadores usuais contém um limite máximo para indicar um sistema partidário com distribuição da representação totalmente proporcional e, assim, plenamente justa. Extensivamente, qualquer desvio em relação a esse número máximo implica certo grau de desproporcionalidade, sempre crescente na medida em que ele se aproxima do limite oposto.

Em virtude disso, a interpretação teórica dos resultados obtidos por qualquer índice de desproporcionalidade da representação é indisputável. Se quisermos, podemos até fazer críticas e objeções técnicas, relativas às operações lógicas das fórmulas utilizadas, como o fazem Taagepera e Grofman (2003), mas não há muito espaço para objeções teóricas acerca do significado dos resultados. Talvez até em virtude disso eles investiram numa avaliação apenas operacional. No entanto, se o exclusivo escrutínio técnico é suficiente para atestar a qualidade dos diversos índices de proporcionalidade da representação, o mesmo não ocorre com o índice de volatilidade eleitoral. Em realidade, ao tratá-lo do mesmo modo que os outros índices, esses autores nos apresentaram uma avaliação dessa medida que é insuficiente.

Em termos teóricos, a literatura de política comparada usualmente tem interpretado o índice de volatilidade eleitoral como um indicador empírico do grau de institucionalização dos sistemas partidários e, com isso, restringiu seus possíveis significados exclusivamente à interpretação sociológica vinculada à teoria do desenvolvimento político, cujo exemplar mais ilustre é a clássica obra de Huntington (1968) . que, por sua vez, foi significativamente influenciado por Parsons. Invariavelmente, os seguidores desse tipo de abordagem interpretam a instabilidade eleitoral como evidência da fragilidade partidária, da baixa efetividade dos governos e da precariedade do próprio regime democrático (por exemplo, Rose \& Urwin, 1970; Przeworski, 1975; Pedeersen, 1979, 1980; Maguire, 1983; Dalton, Flanagan \& Beck, 1984; Shamir, 1984; Crewe, 1985; Bartolini \& Mair, 1990; Mainwaring, 1995, 1998a, 1998b, 1998c, 1999; Mainwaring \& Scully: 1995; Haggard \& Kaufmann, 1995; Pennings, 1998; Kitschelt et al, 1999; Roberts \& Wibbels, 1999; Toole, 2000; Evans, 2002; Toka, 1995, 1998, 2004; Tavits, 2005, 2008a; Mainwaring \& Zoco, 2007). Contudo, conforme pretendo mostrar aqui, esse tipo de interpretação é passível de contestação, seja em termos metodológicos ou teóricos.

Sob tal perspectiva, este artigo tem dois objetivos correlacionados. O primeiro é discutir as anomalias lógicas, conceituais e empíricas da interpretação padrão dos significados da volatilidade eleitoral; o segundo é propor uma interpretação alternativa para o índice. Para tanto, inicialmente, defendo a posição de que existem certas fragilidades lógicas e cosmológicas (concepção do mundo político e de seu funcionamento) que dificultam a fundamentação sociológica das interpretações correntes e, para isso, discuto três problemas básicos geralmente desconsiderados pela literatura. 0 primeiro consiste no paradoxo lógico de que a estabilidade eleitoral pode estar em conflito com a competição partidária, o que significa que a valorização da estabilidade em detrimento da competição desconsidera um dos requisitos básicos da democracia representativa: a efetiva contestação pública (DAHL, 1971). O segundo problema, também de ordem lógica, refere-se ao fato de que não existem critérios incontestáveis que justifiquem a escolha de um determinado ponto ótimo para a volatilidade eleitoral. O terceiro problema, de natureza teórica, reside no fato de que não há uma única maneira de interpretar os significados de cada nível de volatilidade encontrado em cada país específico e, portanto, 
PERES, P. S. Institucionalização do sistema partidário ou evolução da competição?...

precisamos de algum critério para justificar a escolha de um tipo de interpretação em detrimento do outro. Nesse caso, sugiro a adoção do critério de eficiência explicativa.

$\mathrm{Na}$ sequência, defendo outra interpretação para o índice de volatilidade eleitoral, propondo o abandono da perspectiva sociológica, fixamente preocupada com processos de institucionalização, em favor de uma perspectiva econômica, voltada à evolução da competição e dos fatores ambientais. Nesse caso, o sistema partidário deve ser concebido como um dos componentes de um "mercado eleitoral", no qual o grau de restrições (regras e recursos) tem peso significativo na dinâmica da "oferta" (partidos disponíveis e política oferecidas e/ou executadas) e da "demanda" (eleitores individuais, classes econômicas, grupos étnicos, linguísticos ou religiosos e todo o tipo de clivagens sociais). A volatilidade eleitoral indicaria as "oscilações" no mercado político, ou seja, na "oferta" e na "demanda", mediante certos graus de restrições e, em alguns casos, de eventos conjunturais, alheios ou não ao próprio mercado eleitoral. Por isso, os significados dos resultados numéricos encontrados devem ser apreendidos sempre de maneira contextualizada, de acordo com cada situação específica de "oferta/demanda", de restrições e de eventos conjunturais internos e externos ao ambiente eleitoral.

\section{A origem sociológica do índice de volatilidade eleitoral}

Elaborado no contexto do intenso debate acerca da suposta crise dos sistemas partidários europeus nos anos 1960, o índice de volatilidade eleitoral proposto por Pedersen $(1979,1980)$ tinha como finalidade a realização de um teste empírico mais rigoroso da hipótese do "congelamento" dos sistemas partidários daquela região, conforme havia sido afirmado por Lipset \& Rokkan (1967). De certo modo, continha também o propósito de verificar a correção das constatações de Kirchheimer (1966) ${ }^{3}$ acerca dos supostos efeitos da competição eleitoral sobre os partidos europeus. Segundo ele, a intensificação da competição pelo voto depois da Segunda Guerra Mundial atingiu um ponto tão elevado que teria provocado o surgimento de um novo tipo partidário, o partido catch-all, em substituição ao partido de massas, identificado anos antes por Duverger (1951). Aos olhos daquele autor, a emergência desse novo tipo partidário provocaria a indiferença de seus programas e ideologias, redundando na crescente perda da identificação partidária dos eleitores. Evidentemente, uma hipótese plausível a ser deduzida dessa teorização seria o crescimento da volatilidade eleitoral, medida pela diferença agregada na votação dos partidos entre pares sucessivos de eleições. Surgiu daí, então, um intenso debate acadêmico, com sucessivos testes empíricos e com o objetivo de buscar a corroboração ou a refutação da hipótese do aumento da instabilidade eleitoral nos sistemas partidários europeus 4 .

No contexto desse debate, o índice proposto por Pedersen $(1979,1980)$ tornou-se amplamente aceito e utilizado em diversas análises que se sucederam ${ }^{5}$, inclusive nos estudos dedicados às democracias da "terceira onda". Essa transposição do índice, destinado a mensurar a desestruturação dos sistemas consolidados, para os estudos de sistemas em processo de estruturação, deveu-se, principalmente, à defesa teórica que Mainwaring (1995, 1998a, 1998c, 1999) fez da necessidade de se

\footnotetext{
${ }^{3}$ Depois de tantos anos de sua publicação original, em inglês, esse texto clássico foi traduzido em 2012 para o português e publicado pela RBCP, sendo acessível por meio do portal Scielo.

4 Para uma análise histórica e metodológica desse debate, consulte Peres (2005).

${ }^{5}$ Esta é fórmula proposta por Pedersen (1979): VT $=1 / 2 \sum\left|V_{i}, t-V_{i}, t-1\right|$, em que $V t$ representa a volatilidade total ou sistêmica, $V i, t$ a porcentagem de votos obtidos pelo partido $i$ na eleição $t$, e $V i, t \cdot 1$ a porcentagem do partido $i$ na eleição $t \cdot 1$; sendo que $O \leq$ $V T \leq 100$.
} 
considerar o grau de institucionalização dos sistemas partidários como um dos indicadores de consolidação das democracias recentes. Assim, diversas pesquisas acerca dos sistemas partidários da América Latina, da África e do Leste Europeu foram produzidas com essa perspectiva (por exemplo, Remmer, 1991; Mainwaring \& Scully, 1995; Bielasiak, 1997, 2002; Mainwaring, 1995, 1998a, 1998b, 1998c, 1999; Coppedge, 1998; Roberts \& Wibbels, 1999; Kuenzi \& Mabright, 2001; Birch, 2003; Kreuzer \& Pettai, 2003, 2004; Mozaffar \& Scarrit, 2005; Tavits, 2005, 2008a; Mainwaring \& Torcal, 2006; Mainwaring \& Zoco, 2007; Bischoff, 2012). Inclusive, com base nesse índice, houve quem logo tratasse de oferecer rankings de classificação dos países, de acordo com os graus de institucionalização de seus sistemas partidários (MAINWARING \& SCULLY, 1994, 1995).

Em termos cosmológicos, podemos dizer que toda essa literatura contém um viés sociológico. desenvolvimentista bem demarcado. Isso pode ser percebido pela consideração do problema político que motivou a elaboração do índice, bem como sua própria operacionalização. Ele foi concebido para auferir empiricamente a padronização dos comportamentos, a formação de identidades partidárias, a moldagem da mentalidade política dos indivíduos, dos grupos ou das classes, e também para apreender a extensão do enraizamento social dos partidos e da interiorização de normas e valores. Esse fundamento básico é conciliado com a premissa axiológica de que o máximo possível de estabilidade seria algo necessária e inegavelmente bom, logo, absolutamente desejável. A instabilidade, por oposição, seria algo incontestavelmente ruim e, como tal, deveria ser evitada, pois configuraria evidência da falha dos partidos no desempenho das suas indispensáveis funções de "encapsulamento" do conflito social e de formação de identidades políticas.

Com efeito, a volatilidade eleitoral foi concebida como um indicador de instabilidade do próprio sistema partidário, algo já em si problemático. Conforme argutamente observado por Mair (1997) e Tavits (2008b), ao conceber a medida dessa maneira, a literatura acabou tratando erroneamente duas variáveis diferentes, supondo que uma seria apenas um indicador da outra. A instabilidade dos sistemas partidários deve ser entendida como oscilações na "demanda", com frequentes "entradas" e "saídas" de partidos do "mercado eleitoral", de modo que seria possível pensar na hipótese de que a volatilidade eleitoral - oscilações dos votos entre os partidos disponíveis - possa ser decorrente da instabilidade do sistema partidário. Quando a literatura sugere que a volatilidade eleitoral indica o grau de instabilidade do sistema partidário, acaba supondo, inadvertidamente, que a volubilidade do eleitor geraria incerteza nos políticos e partidos, de modo a provocar a instabilidade do sistema partidário. Portanto, a volatilidade eleitoral explicaria a instabilidade dos sistemas partidários, nunca o contrário. Contudo, há fortes evidências de que a volatilidade dos votos muitas vezes ocorre em resposta às estratégias das lideranças políticas, que promovem constantes alterações na "oferta partidária", ou seja, ocorrem em função da instabilidade dos sistemas partidários (MAIR, 1997; TAVITS, 2008b; PERES, RICCI e RENNÓ, 2011; BISCHOFF, 2012)

Além disso, por considerarem a estabilidade eleitoral um bem autoevidente, os analistas costumam prescrever o que consideram os arcabouços institucionais mais propícios à formação de vínculos societários irrompíveis entre os indivíduos e as organizações partidárias. Isso é reforçado pelo

\footnotetext{
${ }^{6}$ Além de tais pesquisas empíricas, alguns autores vêm, há algum tempo, apresentando sérias críticas acerca dessa suposta relação. Sobre isso, ver, por exemplo: Crewe (1985), Mair (1997), Toole (2000), Laver and Benoit (2003), Kreuzer \& Petta (2004).
} 
PERES, P. S. Institucionalização do sistema partidário ou evolução da competição?...

peso que os pesquisadores atribuem aos componentes afetivos envolvidos no processo político-eleitoral. Para os adeptos dessa perspectiva, no limite, e por analogia, votar em um partido seria o mesmo que torcer por um time, ou seja, um ato passional e incondicional. Consequentemente, mesmo que o time de algum torcedor esteja em último lugar no campeonato, não seria admissível que ele simplesmente o trocasse por outro. Em última instância, a competição teria que se manter em um nível mínimo, o máximo possível, ou talvez até inexistir, de modo que a estabilidade pudesse ser seguramente garantida e duradoura.

Mas, será mesmo que a estabilidade eleitoral é sempre boa e, contrariamente, a instabilidade eleitoral é sempre ruim? Em decorrência de sua orientação teórica e valorativa, os estudos realizados sobre o tema julgavam que sim, afinal, já estavam "pré-programados" para interpretar a volatilidade eleitoral como um sinal do aterrorizador "espectro da instabilidade" política, conforme já observado por Bartolini e Mair (1990). Condicionados por uma perspectiva sociológica demasiadamente comprometida com o projeto normativo da teoria do "desenvolvimento político", os estudiosos do fenômeno, conscientes disso ou não, ficaram impedidos de explorar outras interpretações possíveis para a instabilidade eleitoral e acabaram desconsiderando a possibilidade de que a mesma possa estar associada ao comportamento estratégico dos atores políticos, e não a qualquer sinal de implosão do sistema partidário. Mais do que isso, tal tipo de interpretação incorre em dois problemas lógicos que fragilizam a fundamentação dos significados usualmente atribuídos à volatilidade eleitoral. 0 primeiro deles decorre das consequências de se admitir que o melhor sistema seria aquele que promovesse uma estabilidade total, sem nenhuma alteração nas votações partidárias. Ou seja, sendo "Ve" a volatilidade eleitoral, logo, o ideal seria: $V e=0$. O segundo, contrariamente, decorre das consequências de se admitir que um mínimo de instabilidade seria desejável, de forma que pudesse existir uma pequena oscilação nos apoios eleitorais dos partidos, garantindo, assim, algum grau de competição política. Portanto, nesse caso, o ideal seria: $V e \neq 0$. Porém, que número, diferente de zero, deveríamos tomar como o ponto ótimo ou ideal? Vejamos mais detalhadamente esses problemas.

\section{O dilema estabilidade eleitoral/competição partidária}

O que ocorreria se todos os eleitores sempre votassem da mesma forma? Quais as consequências desse tipo de comportamento para a própria efetividade da democracia? Logicamente, se todos votassem sempre do mesmo modo, o que teríamos é que o grupo eventualmente majoritário tornar-se-ia continuamente majoritário. E tal quadro não seria alterado nem mesmo com a entrada de novas gerações no sistema político, uma vez que tais indivíduos seriam socializados pelos grupos pré. existentes e predominantes no status quo, conforme suposto pelas abordagens sociológicas. desenvolvimentistas. Se fosse assim, invariavelmente, o mesmo grupo majoritário venceria as eleições. Isso mostra que a interpretação sociológica usual para o Índice de Volatilidade Eleitoral enfrenta uma importante contradição lógica que resulta em um problema teórico e, em grande parte, normativo: a proposição de estabilidade total, ou $\mathrm{Ve}=0$, vai frontalmente de encontro com o requisito democrático da competição política e da alternância no poder, ou $V e \neq 0$.

$\mathrm{Na}$ verdade, é forçoso lembrar, tal problema nos remete precisamente àquela que sempre foi a maior preocupação dos teóricos que se ocuparam com a reflexão acerca da melhor forma de governo, qual seja, a "degeneração" daquele que consideravam um dos melhores regimes possíveis - a politeia ou 
república. Podemos perceber em Aristóteles (1999), por exemplo, a concepção de que a democracia, entendida como governo da maioria, no caso, o demos, consistiria na degeneração da república ou, mais propriamente, do governo de todos, em uma tirania do grupo majoritário. Tal governo seria tirânico porque atenderia somente aos interesses da maioria enquanto uma classe social, e não aos interesses de toda a comunidade; e, acima de tudo, porque essa maioria seria altamente coesa e, por extensão, sempre única e totalmente estável.

A mesma preocupação aparece nos escritos dos filósofos políticos modernos, como Locke (1980) e Montesquieu (1949), cujas tentativas teóricas e normativas de propor antídotos contra qualquer tipo de tirania se voltavam às idealizações de arranjos institucionais capazes de desvencilhar a sociedade civil seja da opressão de um governo concentrado na ínfima minoria da autocracia do monarca absolutista, seja da opressão de um governo da maioria invariável. E não nos esqueçamos da problemática magnitude de tal maioria que, pela lógica da decisão majoritária por maioria absoluta, contém intrinsecamente a propensão a atingir qualquer ponto mínimo acima dos 50\%, ou seja, aquele ponto máximo minimamente necessário para formar a maioria ao qual Riker $(1962,1982)$ reportou-se em sua teoria da formação de coalizões. Isso significa que a parcela considerada minoritária pode corresponder a um máximo, digamos, $X$, tal que $49 \% \leq X<50 \%$ - sem contar os casos de vitória da "maior minoria", garantida pelas decisões por maioria relativa ou pluralidade.

Semelhante preocupação mobilizaria igualmente as reflexões de Stuart Mill (1952), que chegaria a considerar que os governos dos Estados Unidos e da Inglaterra operariam "falsas democracias". Vislumbrando problema semelhante, Hamilton, Madison \& Jay (1952) defenderam nos artigos "Federalistas" a engenharia constitucional debatida e concretizada pela Convenção de 1787, a qual continha o propósito de limitar ao máximo a concentração de poder - seja no governo central (república), nos governos locais (federalismo) ou na maioria popular (democracia) -, de tal forma que pudessem ser erguidos vários obstáculos político-institucionais à "degeneração" da república representativa ou, mais precisamente, à emergência de um governo puramente democrático (cf. Dahl, 1956, 2003). Obviamente, aqueles políticos e pensadores concebiam a democracia de modo similar ao dos filósofos clássicos e modernos, ou seja, como um governo da maioria estável e imutável, como um governo capaz de tiranizar as diversas minorias. Tocqueville (1991), como se sabe, foi um dos que elogiaram com maior entusiasmo esse desenho constitucional, destacando seu "realismo" ao aceitar o inexorável advento da democracia - ou da incorporação do demos à polis ·, mas de conferir-Ihe, simultaneamente, os elementos "virtuosos" da aristocracia - eleições e representação - e os devidos controles mútuos constitucionalistas dos checks and balances, tão indispensáveis às liberdades dos indivíduos e das minorias contra a tirania da maioria.

Como é possível perceber, na perspectiva teórica de todos esses autores, há uma contraposição radical entre a república e a democracia, consideradas como formas de governo antagônicas, porém, de certo modo, interligadas como os dois pontos extremos de uma mesma linha. Na república, todos os cidadãos participariam das decisões políticas, procurando atender aos interesses coletivos. Porém, em termos práticos, a sociedade civil seria dividida em classes ou grupos, com interesses específicos e tão diferenciados a ponto de serem contrários. A lógica das decisões coletivas levaria, portanto, à união dos indivíduos, em princípio, dispersos, de modo que se formariam grupos sociais bem delimitados e 
PERES, P. S. Institucionalização do sistema partidário ou evolução da competição?...

diretamente concorrentes nas assembleias. Assim, aquele grupo ou aquela coalizão de grupos que se constituir como a vontade majoritária estaria automaticamente habilitado/a a determinar em seu favor toda e qualquer decisão coletiva; mas, é claro, sob a condição de manter-se sempre coeso/a e maximamente estável. Portanto, a degeneração da república em democracia envolve precisamente a configuração de um cenário no qual as decisões coletivas são completamente estáveis, em decorrência da manifestação de interesses e identidades imutáveis.

Retornando ao problema da volatilidade eleitoral, podemos concluir que se a socialização dos indivíduos em um determinado grupo e sua consequente identificação com o mesmo criariam o ambiente de plena estabilidade tão reivindicado por vários analistas atuais, em contrapartida, tal estabilidade poderia significar igualmente a emergência de uma tirania do grupo majoritário ${ }^{7}$. Então, há, claramente, uma contradição lógica, e, poderíamos até dizer, normativa em se admitir que a alternância no poder seria um requisito e um indicador importante da qualidade da democracia e, ao mesmo tempo, defender que esta será tanto melhor quanto maior for a estabilidade do comportamento eleitoral, já que, neste "quanto maior for" está contida a consequência lógica da regressão até o valor mínimo, o que necessariamente conduz à defesa da estabilidade total. Inclusive, esta distensão do argumento já permite a refutação dessa ideia pelo recurso do reductio ad absurdum, uma vez que sem competição é difícil conceber a própria democracia representativa. Ou seja, se a democracia demanda a possibilidade de alternância no poder, por princípio, demanda também algum grau de instabilidade, o que significa que nem toda estabilidade deve ser boa, como a estabilidade total, e nem toda instabilidade deve ser ruim, como a instabilidade associada à competição política e, por extensão, à rotatividade no poder.

Tais dificuldades mostram, portanto, a impossibilidade da defesa de algum tipo de juízo de valor prévio em relação à instabilidade/estabilidade das votações, conforme preconizado pelo viés sociológico-desenvolvimentista. Além disso, constituem um indicativo da necessidade de ser abandonada qualquer posição normativa absoluta em relação ao índice de volatilidade eleitoral e, com ela, o abandono da preocupação metodológica e axiológica de se mensurar a institucionalização dos sistemas partidários, bem como de julgá-los em função disso.

\section{Impossibilidade da determinação do valor ótimo para a volatilidade eleitoral}

Enfrentemos agora o segundo problema lógico apontado anteriormente, que consiste na defesa da articulação de duas premissas normativas que preconizam o máximo de estabilidade possível, porém, com algum grau de instabilidade, ou seja: $V e \neq 0$. Este, na verdade, é um posicionamento amplamente compartilhado por vários estudiosos de política comparada e, certamente, deve-se à tentativa de compatibilizar a busca da estabilidade dos sistemas partidários com o requisito democrático de competição eleitoral. Afinal, conforme observam Bartolini e Mair, os pesquisadores perceberam-se premidos por duas orientações aparentemente inescapáveis: "on the one hand, long-term electoral stabilization appears as a necessary prerequisite for democratic consolidation. On the other hand, a

\footnotetext{
7 Kelsen referiu-se a isso com reprimenda, sendo um dos primeiros a observar que a ampla defesa do princípio de representação majoritária, mediante a adoção de um sistema eleitoral do tipo "o-vencedor-leva-tudo", deveria atentar para o fato de que esse sistema deveria contar, ex-ante, com distritos - ou constituencies - socialmente heterogêneos, sob pena, em caso contrário, de não produzir quaisquer alternâncias nos poderes executivo e legislativo. Tais argumentos podem ser encontrados numa edição em português de uma coletânea de textos de Kelsen (1993), publicados em datas e meios variados. Confira especialmente os primeiros três capítulos, referentes aos textos Vom Wesen und Wert der Demokratie, de 1929, Das Problem des Parlamentarismus, de 1924, e Foundations of Democracy, de 1955.
} 
degree of electoral instability also appears to be necessary in order to ensure democratic responsiveness and accountability" (BARTOLINI \& MAIR, 1990, p. 3).

Diante disso, temos agora outro problema lógico a ser atacado. Quando a literatura adere àquelas duas diretrizes normativas - estabilidade eleitoral com competição partidária ., automaticamente, está a sugerir que há um nível de volatilidade eleitoral que não apenas é aceitável como, acima de tudo, é desejável. Se for este o caso, a questão agora é determinar o ponto ótimo da instabilidade eleitoral, ou seja, algum número $[X]$ que corresponda a $V e \neq 0$. Mas, precisamente que número seria esse? Para sua determinação é imprescindível que encontremos certos critérios endógenos ao índice, os quais possam permitir a conciliação de um nível de volatilidade eleitoral suficiente para a vigência da competição democrática, por um lado, com um nível necessário de estabilidade eleitoral para expressar a institucionalização do sistema partidário, por outro.

Sabemos de antemão que ninguém recomendaria um sistema partidário que tivesse oscilação nas votações igual a zero, portanto, uma completa estabilidade eleitoral. Do mesmo modo, ninguém recomendaria que esse mesmo sistema apresentasse taxas de oscilação muito elevadas, algo em torno de $20,30,40 \ldots 100$ pontos - na literatura especializada, encontramos autores que consideram alta uma volatilidade acima de 10 ou 15. Assim, a única certeza da qual podemos partir é que sempre seria preferível estabilidade eleitoral o mais próxima de zero tanto quanto possível. Mas quanto? ${ }^{8}$ Há duas alternativas que poderiam ser pensadas como "soluções" metodológicas para esse problema. Poderíamos supor critérios para a adoção de um ponto ótimo absoluto, ou então para a adoção de um ponto ótimo relativo. Não obstante, a verdade é que, mesmo nesses casos, não há critérios lógicos que possam determinar um grau inequivocamente defensável no intervalo entre 0 e 100 do índice de volatilidade eleitoral capaz de garantir um valor ótimo para a coexistência de estabilidade eleitoral com competição partidária.

Consideremos o caso do ponto ótimo absoluto - um valor fixo determinado endogenamente. As tentativas de fundamentar critérios justificáveis para sua adoção resultariam, invariavelmente, na consequência contraditória de que o nível encontrado será sempre tão próximo de zero ou da estabilidade total que a diferença entre $\mathrm{X}$ e 0 seria quantitativamente desprezível. Isso ocorre porque, ao partirmos da premissa inevitável de que é sempre preferível o maior grau de estabilidade possível, incorremos no problema da regressão até quase-zero e, no limite, até zero. Sendo assim, anula-se o segundo termo axiológico do problema, que é a manutenção de uma taxa minimamente satisfatória e necessária de competição partidária.

Tampouco é possível defender um ponto ótimo absoluto em termos meramente convencionais . escolhido, por intuição ou "bom-senso" pelo próprio pesquisador -, uma vez que sempre serão cabíveis sucessivos questionamentos do porquê da não-adoção de um grau imediatamente inferior. Por exemplo, se propusermos, convencionalmente, que a volatilidade eleitoral ótima deva ser 1 , poderíamos contrapropor outros níveis, tais como 0,9; ou 0,8; ou 0,7; ou 0,6; ou ainda 0,02; 0,00000001... n. Se tentarmos evitar esse ciclo de redução até o ponto zero, afirmando que o desejável é um grau máximo de estabilidade, mas diferente de zero, voltamos mais uma vez à espiral lógica evidenciada pela redução até

\footnotetext{
8 Nem mesmo os critérios de Taagepera (2008) para a determinação de X diante da informação apenas dos limites mínimo e máximo de um contínuo, por meio da aproximação pela média geométrica, resolveria essa questão.
} 
PERES, P. S. Institucionalização do sistema partidário ou evolução da competição?...

zero, sem chegarmos a um número preciso e inquestionável. Sendo assim, não há justificação lógica para qualquer ponto específico para o índice de volatilidade eleitoral em termos absolutos que contemple, simultaneamente, as duas premissas normativas inerentes ao problema.

A outra "solução" cogitável seria a defesa de um ponto ótimo relativo, que poderia ser a média aritmética ou geométrica de um conjunto de valores observados ou, então, a menor volatilidade eleitoral encontrada empiricamente em um conjunto de sistemas partidários analisados, seja diacrônica ou sincronicamente. Porém, no caso das médias, dependemos do grau de dispersão da distribuição, pois a variabilidade pode ser tão grande que a média deixaria de ser representativa. Mas, mesmo que a distribuição seja bastante centralizada, ainda assim, teremos a dificuldade de propor um ponto ótimo relativo estático para uma medida que é essencialmente dinâmica; e isso também se aplica ao caso da adoção do menor valor encontrado. Com efeito, a própria orientação histórica da medida inviabiliza a adoção de um critério relativo, uma vez que os elementos mais importantes a serem considerados são as variações temporais dos valores, e não a média ou o menor valor de um dado período. A Tabela 1 traz simulações que exemplificam alguns desses problemas:

Tabela 1

Simulação de volatilidades eleitorais hipotéticas

\begin{tabular}{|c|c|c|c|}
\hline Países & $1^{\circ}$ Par de Eleições & $2^{\circ}$ Par de Eleições & $3^{\circ}$ Par de Eleições \\
\hline Inglaterra & 4 & 8 & 8 \\
\hline Bélgica & 8 & 10 & 6 \\
\hline França & 10 & 16 & 12 \\
\hline
\end{tabular}

Como se pode perceber, no tempo t1 dessa hipotética série histórica encontramos a Inglaterra, a Bélgica e a França, com os índices de volatilidade respectivos de 4, 8 e 10. No tempo t2, encontramos, também respectivamente, 8,10 e 16. Assim, se fôssemos adotar um critério relativo, teríamos uma variação que levaria a uma inconsistência, dado que, no primeiro par de eleições, a Inglaterra seria tomada como o ponto ótimo da volatilidade eleitoral $(V e=4)$; no segundo, a mesma Inglaterra ainda seria o ponto ótimo, mas com o dobro da volatilidade anterior $(\mathrm{Ve}=8)$, valor que, aliás, era o segundo menor em t1, obtido pela Bélgica. Se houvesse ainda uma nova sequência hipotética, t3, com os resultados respectivos de 8,6 e 12, teríamos agora a Bélgica como o ponto ótimo de volatilidade eleitoral, sendo que a Inglaterra, mesmo mantendo o resultado de t2, quando propiciou o ponto ótimo daquele par de eleições, ficaria agora com o segundo melhor resultado. Enfim, como chegar, desse modo, a qualquer determinação relativa sustentável?

É possível concluir, então, que não há um critério de quantificação justificável para a determinação de um ponto ótimo para a volatilidade eleitoral, seja em termos relativos ou absolutos. É impraticável a identificação certa e segura, seja lógica, convencional ou empírica do nível mínimo de instabilidade para a existência de competição num dado sistema partidário. Ademais, a competição pode ser variável em função de $n$ fatores, de modo que aquele mesmo montante de volatilidade que implicou na disputa partidária efetiva em uma eleição pode não ser suficiente para representar a mesma coisa em outra eleição. 
OPINIÃO PÚBLICA, Campinas, vol. 19, no 1, junho, 2013, p. 21-48

Sendo assim, as únicas proposições logicamente aceitáveis na análise são as seguintes: a) nenhuma volatilidade eleitoral significa nenhuma competição, b) qualquer valor no intervalo acima de 0 até 100 indica algum grau de oscilação na votação proporcional dos partidos em competição e, c) comparativamente, há países com diferentes níveis de volatilidade eleitoral. Porém, de forma alguma, é possível emitir qualquer juízo de valor acerca da posição de um determinado país em relação a um suposto nível ideal de estabilidade. Consequentemente, ou bem se advoga a estabilidade total, à custa do requisito democrático da efetiva competição partidária, ou bem se admite a necessidade da competição e, extensivamente, da instabilidade eleitoral, e em graus variados. Mas, nesse caso, será preciso interpretar a volatilidade eleitoral como outra coisa que não um indicador de crise de institucionalização dos sistemas partidários.

\section{Comparando os Modelos: em busca da "Eficiência Explicativa"}

Se encontrássemos, por exemplo, um índice de volatilidade eleitoral igual a 20 em um dado par de eleições, e se tivéssemos que afirmar algo acerca do significado teórico desse número, o que exatamente poderíamos dizer? De acordo com o posicionamento padrão da literatura de política comparada, a interpretação correta a ser feita é que estaríamos diante de um sistema partidário bastante instável e que isso seria um indicativo de uma falha no processo de institucionalização dos partidos, resultante ou de algum grau de debilidade cognitiva dos eleitores, ou de algum grau de debilidade organizacional dos partidos, incapazes de estabelecer o enraizamento social da representação e de formar identidades políticas sólidas e duradouras, ou, ainda, da conjunção desses dois fatores.

Contudo, seria plenamente justificável a interpretação teórica de que a instabilidade eleitoral é indicativa de pouca racionalidade dos indivíduos, ou de debilidade institucional, ou de baixa institucionalização partidária? E mais, seria essa a única interpretação possível para o grau de volatilidade eleitoral encontrado? As respostas são negativas para todas as perguntas, porque, em primeiro lugar, é importante observar que mesmo que houvesse apenas um tipo de interpretação para o índice e esse tipo fosse exatamente aquele, já estaríamos diante de sérios problemas lógicos, como discutido anteriormente. Em segundo lugar, há uma teoria explicativa concorrente, que traz a possibilidade de outra interpretação para a volatilidade eleitoral, sem recorrer ao conceito de institucionalização e à concepção sociológica de desenvolvimento político. Trata-se da abordagem institucional-racionalista.

Por um lado, temos o paradigma sociológico, que se manteve hegemônico nas explicações do comportamento político desde a conhecida "revolução comportamentalista" 9 iniciada nos anos 1940; por outro, temos o paradigma neoinstitucional de vertente racionalista, baseado nas premissas da teoria da escolha racional e nos paradoxos descobertos pela teoria da escolha social, a qual foi responsável pelo retorno das instituições ao centro da análise política ${ }^{10}$. No âmbito do paradigma sociológico, a instabilidade eleitoral deve ser entendida como algo sempre negativo, prejudicial à democracia, porque, conforme já mencionado, trata-se de uma evidência de falha institucional nos processos de formação das

\footnotetext{
${ }^{9}$ Sobre a revolução comportamentalista na Ciência Política, consulte Eulau, Eldersveld and Janowitz (1956), Butler (1958), Dahl (1961), Easton (1962), Charlesworth (1962), Ranney (1962), Eulau (1963). Para uma análise histórica e epistemológica de sua evolução e de sua contestação pelo recente paradigma neoinstitucionalista, consulte Peres (2008).

${ }^{10}$ Maiores detalhes acerca das diferentes escolas no âmbito do neoinstitucionalismo podem ser encontrados nas análises classificatórias de March \& Olsen (1984), Hall \& Taylor (1996), Noorgard (1996), Kato (1996) e Peres (2007).
} 
PERES, P. S. Institucionalização do sistema partidário ou evolução da competição?...

identidades políticas. Inversamente, de acordo com o paradigma institucional-racionalista (IR), a instabilidade eleitoral também pode ser entendida como algo positivo, na medida em que se pode adotá. la como evidência da racionalidade instrumental dos atores que, ao tomarem a decisão do voto, considerariam algumas estratégias alternativas e, acima de tudo, procederiam uma avaliação projetiva/retrospectiva em relação ao partido do governo e ao partido oponente. A instabilidade eleitoral, então, poderia ser resultante de uma escolha racional, baseada em um cálculo utilitário envolvendo os benefícios passados e presentes, assim como os benefícios futuros almejados pelos indivíduos ${ }^{11}$.

De modo geral, essas duas perspectivas são concorrentes principalmente porque: a) partem de premissas teóricas opostas, b) utilizam princípios metodológicos díspares e c) levam a interpretações divergentes no que se refere aos significados do índice de volatilidade eleitoral. A consideração comparativa desses elementos, conforme as informações dispostas no Quadro 1, permite-nos captar as principais diferenças teóricas em questão. Note-se que a abordagem sociológica toma os agregados sociais como unidade de análise, ou seja, as classes ou os grupos. A adoção de tal foco analítico ocorre em consequência da concepção teórica de que essas entidades seriam as mais fundamentais para a produção e a manifestação dos fenômenos políticos. Devido à ênfase nos processos de socialização, sua variável explicativa principal é a formação de identidades partidárias e seu fundamento explicativo é voltado ao vínculo afetivo entre os atores e as instituições sociais e políticas. Em oposição, a abordagem institucional-racionalista (IR) considera que as entidades fundamentais dos processos políticos são os indivíduos, cuja característica básica seria o cálculo racional-instrumental. Daí seu fundamento explicativo ser a racionalidade - entendida como capacidade de escolha estruturada de forma coerente e ordenada - e a variável explicativa das ações ser a preferência, que é expressa por meio de um sistema lógico de escolhas pareadas nos momentos da tomada de decisão. Esta, por sua vez, é o objeto privilegiado desse tipo de análise.

Quadro 1

Comparação dos elementos teóricos das explicações sociológica e institucional-racionalista

\begin{tabular}{|c|c|c|}
\hline Elementos Teóricos & Abordagem Sociológica & Abordagem IR \\
\hline Unidade de Análise & Classe/Grupo Social & Indivíduo \\
\hline Fundamento Explicativo & Afetividade & Preferência Política \\
\hline Variável Explicativa & Identidade Política & Escolha/Decisão \\
\hline Objeto de Análise & Vínculo Social & Competição \\
\hline Conceito Central & Instabilidade/Estabilidade & Decisão Racional Estratégica \\
\hline Significado da Volatilidade & Falha/Crise Institucional &
\end{tabular}

\footnotetext{
11 Na terminologia de Downs (1957), tal escolha seria o resultado de um cálculo do diferencial partidário. Em termos formais, o autor apenas indica a estrutura algébrica de tal cálculo em situações nas quais competem dois partidos, de modo que os diferenciais seriam, na realidade, diferenciais bipartidários, mas o raciocínio é aplicável também a sistemas multipartidários. Com relação ao cálculo dos diferenciais bipartidários, a lógica é tal que $E\left(U^{A(t+1)}\right)-E\left(U^{B(t+1)}\right)$, no caso de cálculo projetivo, é tal que $\left(U^{A(t)}\right)-E\left(U^{B(t)}\right)$, no caso do cálculo retrospectivo; sendo $E$ o eleitor, $U$ a utilidade esperada, como na primeira equação, ou a utilidade obtida, como na segunda equação, sendo $A$ e $B$ os partidos em competição e $t$ e $t+1$ os tempos considerados.
} 
Podemos notar ainda que as duas perspectivas apresentam explicações condizentes com suas respectivas premissas, ou seja, dados seus elementos teóricos, forma-se determinado sistema de inferências cujo enunciado sintético (predicação) impõe certo significado à instabilidade eleitoral, significado este produzido por uma decorrência lógica. Assim, é mesmo esperável que aqueles que adotem a perspectiva sociológica apreendam a instabilidade enquanto um problema político ou social, afinal, todo seu sistema de inferências foi montado para perceber, a priori, a instabilidade como evidência de crise institucional. Do mesmo modo, é esperado que aqueles que adotam a perspectiva institucional-racionalista (IR) apreendam a instabilidade como algo que também pode ser, digamos, uma "virtude" ou uma indicação de funcionamento adequado da competição política e da racionalidade instrumental dos indivíduos. Seu sistema de inferências é equipado para perceber a instabilidade por intermédio de um enquadramento conceitual no qual ser volátil pode significar ser racional mediante os incentivos institucionais.

Mas, se as interpretações inferem conclusões opostas e conflitantes acerca do mesmo objeto, o que temos é que, por lógica, uma delas - ou as duas (deixemos espaço aqui para possíveis críticas e inovações) - deve estar equivocada, pois ambas não podem estar simultaneamente corretas. Isso significa que é preciso encontrar justificativas para a adoção de uma ou de outra interpretação. Nesse caso, a escolha de um desses dois paradigmas concorrentes pode ser feita com base no critério de eficiência explicativa. Ou seja, o paradigma que se mostrar mais eficiente na explicação do objeto em suas mais variadas nuances, consequentemente, mostrar-se-á o mais adequado do ponto de vista interpretativo.

Como vimos, a abordagem sociológica adotou uma perspectiva evolucionista teleológica, supondo que os partidos de massas seriam o cume do desenvolvimento das organizações representativas (hipótese empírica); também supôs que tais partidos deveriam socializar politicamente os indivíduos, representar interesses de grupos ou de classes, possuir uma ideologia clara e imutável, defender um programa de governo inegociável e ser liderados por dirigentes implacáveis no cumprimento do estatuto, o qual, por sua vez, deve definir uma organização estruturalmente rígida, centralizada e disciplinada, porém, democrática ${ }^{12}$ (proposições normativas). Foi mencionado também que a emergência dos partidos catch-all foi vista como ameaça ao sistema representativo ou, no mínimo, como um sinal de subdesenvolvimento partidário. Por isso, quando surgiram novos partidos que desafiavam os já consolidados, em meados da década de 1960, e quando a instabilidade eleitoral apresentou um consequente incremento nos anos subsequentes, inúmeros analistas mostraram-se extremamente alarmados, concluindo que a estrutura de clivagens na Europa estaria esfacelando-se e, com ela, o próprio sistema representativo.

Diante de tal cenário, alguns analistas culparam os próprios partidos pela crise iminente, devido à sua transformação organizacional e à sua atuação pragmática, voltada apenas à competição

\footnotetext{
12 Claramente, grande parte da literatura (por exemplo, Mainwaring, 1995, 1998b, 1999) incorreu numa contradição resultante de um equívoco interpretativo. Supuseram erroneamente que os partidos de massas descritos por Duverger (1951) eram organizações disciplinadas e democráticas ao mesmo tempo. Na verdade, fazendo eco da teoria de Michels, Duverger descreve o partido de massas como uma estrutura organizacional altamente centralizada e burocrática, bem distante de qualquer modelo decisório democrático. Nesse caso, Panebianco (1982) teve percepção mais correta, pois não vinculou a democracia interna à estrutura organizacional consolidada. Não obstante, ele ainda recorre à concepção de "institucionalização" para estudar as organizações partidárias e, com isso, também acaba aderindo à perspectiva normativa que concebe a estabilidade e a centralização como objetivos desejáveis a qualquer partido que se queira institucionalizado.
} 
para a vitória eleitoral - tese da "descaracterização" dos partidos ; outros analistas culparam os eleitores, cada vez mais apáticos e desinteressados pela política e pelo governo - tese da "alienação" política. Uma terceira vertente resolveu culpar a dissintonia do sistema político em relação às mudanças estruturais da sociedade e à emergência de uma era pós-industrial, com novos valores e demandas por mecanismos alternativos de participação e de representação políticas - tese da emergência de valores "pós-materiais"13.

Não obstante, conforme mostraram Bartolini e Mair (1990) e Mair (1997), a propagada instabilidade eleitoral europeia a partir dos anos 1960 era, na verdade, um mito. De acordo com eles, já havia ocorrido instabilidade alta antes desse período e, considerados em termos gerais, índices elevados de volatilidade eleitoral não eram predominantes na região. Além disso, o incremento da instabilidade dos sistemas partidários não significou nenhuma ruptura na representação política das clivagens partidárias e muito menos crise dos partidos já consolidados; pelo contrário, tanto as clivagens como os partidos tradicionais permaneceram relativamente estáveis ${ }^{14}$. Ademais, as mudanças nas organizações e nas ações partidárias não necessariamente são sinais de crise, mas de adaptação ao ambiente eleitoral. De fato, alguns estudos mostram que os partidos vêm se transformando em termos organizacionais e estratégicos, com a finalidade de adaptaram-se às mudanças sociais e ao novo ambiente político, cada vez mais competitivo em termos eleitorais. Desse modo, ao invés de crise, a volatilidade poderia representar um processo de mudanças no ambiente eleitoral e nas organizações partidárias (cf. Strøm, 1990; Katz \& Mair, 1994, 1995, 1996; Kitschelt, 1994; Aldrich, 1995; Maor, 1997; Müller and Strøm, $1999)^{15}$.

Por que, então, a abordagem sociológica deduz um mundo de crises quando se depara com a instabilidade eleitoral? Porque, como já mencionado, essa teoria não pode mesmo perceber outra coisa que não um vínculo direto e estreito entre instabilidade e crise. Então, o que fazer quando suas interpretações e previsões não encontram correspondência empírica? A "solução" tem sido o investimento no "espírito de tenacidade", de forma que a literatura continua a interpretar a instabilidade eleitoral como indicador de alguma crise institucional; e nada mais do que isso. Porém, a anomalia empírica da interpretação sociológica, sem contar suas inconsistências lógicas já discutidas, mostra que o paradigma estrutural-funcionalista da teoria do desenvolvimento político tem sérias falhas lógicas e conceituais, e que, por isso, é necessário que busquemos um paradigma alternativo mais eficiente.

\footnotetext{
13 Toda essa literatura é muito extensa, de modo que não cabe citar aqui cada uma das referências. Porém, presumo que sejam referências já amplamente conhecidas e que serão devidamente reconhecidas pela menção dos enfoques analíticos.

14 Conforme evidenciaram os dados sobre a volatilidade entre blocos partidários. Para isso, Bartolini and Mair (1990) propuseram uma pequena, mas importante, inovação na medida, sugerindo que dever-se-ia mensurar também a volatilidade entre blocos partidários, agrupados segundo ideologia, ou religião, ou qualquer outro tipo de orientação. Sua formalização matemática é a mesma proposta por Pedersen (1979), com a diferença de que onde se consideram as proporções de votação dos partidos individuais deve se considerar as proporções dos votos obtidos por um conjunto de partidos, agrupados em blocos ou famílias.

15 É importante observar que, nos últimos 20 anos, a volatilidade eleitoral vem aumentando em diversos países da região, o que levou Mair (2003) a praticamente reconhecer que haveria uma crise partidária e a possível emergência de uma contraditória "democracia sem demos". A identificação e a filiação partidárias, assim como o comparecimento eleitoral também apresentam reduções significativas em alguns países e na média regional. Contudo, conforme podemos deduzir das características centrais do novo tipo partidário caracterizado por Katz e Mair (1995, 1996), talvez nunca antes os partidos estiveram tão fortes como atualmente, pois além de centrais para o processo governamental, ocupam cada vez mais espaço na esfera estatal, paralelamente a ou em detrimento da burocracia. Portanto, ainda não parece ser possível supor que a volatilidade europeia possa ser indicador de algum processo de crise dos sistemas partidários, mas, talvez, de grandes alterações do "mercado eleitoral".
} 
Nesse caso, será que a analogia do ambiente eleitoral com um mercado, no qual ocorrem transações entre atores racionais (instrumentais) mediante uma dinâmica de "oferta/demanda", de acordo com certas restrições (regras e recursos), poderia evitar as anomalias explicativas (lógicas e empíricas) do paradigma sociológico? Considerando que a resposta à pergunta é positiva, procuro, na sequência, justificar a adoção da interpretação institucional-racionalista (IR) para o índice de volatilidade eleitoral. Para tanto, o eixo da discussão deve ser mudado, adotando-se o conceito de competição interpartidária no lugar do conceito de institucionalização do sistema partidário. Com esta substituição, a estabilidade deixa de ser o objetivo final ou teleológico de um sistema partidário e a análise pode concentrar-se nos elementos que mais propriamente caracterizam a democracia contemporânea (cf. Dahl, 1956, 1971; Lijphart, 1969, 1977, 1984, 1999), quais sejam: a multiplicidade de partidos representando a variabilidade de políticas possivelmente almejadas pelos indivíduos, a liberdade de "entrada" dos partidos no mercado político, a liberdade para os indivíduos expressarem suas preferências diante de uma variedade de alternativas, a possibilidade de coordenação de estratégias coletivas e de alianças políticas que induzam à negociação e à moderação, a formação de maiorias amplas, etc.

\section{Heurística de uma interpretação econômica}

Alguns pesquisadores de política comparada já resvalaram tangencialmente em uma interpretação econômica dos possíveis significados da volatilidade eleitoral. Em linhas gerais, essas abordagens podem ser enquadradas em dois tipos: o modelo do voto retrospectivo ${ }^{16}$ e a explicação político-institucional. No primeiro caso, os pesquisadores enfatizam a racionalidade econômica dos eleitores enquanto "consumidores" de políticas públicas que procuram maximizar seus interesses, por meio do voto retrospectivo ou de outros ganhos eleitorais (por exemplo, Powell, 1981; Strøm, 1985; Lewis-Beck \& Stegmaier, 2000; Bengtsson, 2004; Matilla \& Raunio, 2004). As variáveis usualmente associadas à volatilidade são indicadores do desempenho macroeconômico, tais como inflação, taxa de emprego, nível de renda, etc. No segundo caso, os pesquisadores procuram associar a volatilidade ao sistema eleitoral, especialmente o número de partidos (ELKINS, 1974; PEDERSEN, 1979, 1980; CREWE \& DenVer, 1985; Bartolini \& Mair, 1990; Remmer, 1991; Strøm, 1992; TAVITS, 2005, 2008a, 2008b; BISCHOFF, 2012).

Como se sabe, Pedersen $(1979,1980)$ foi um dos primeiros a sugerir, de maneira mais sistemática, que a volatilidade eleitoral estaria associada à competição partidária, ao perceber que o aumento do número de partidos levou ao incremento da instabilidade dos sistemas partidários europeus. Para fundamentar essa hipótese, recorreu ao modelo de competição espacial proposto por Downs (1957), alegando, inclusive, que haveria uma correlação consistente entre a preferência dos indivíduos e a posição dos partidos em um dado contínuo unidimensional, no qual determinados "pacotes" de políticas públicas de certo teor ideológico estariam distribuídos. Seguindo o mesmo mote, Bartolini e

\footnotetext{
16 Nesse caso, é importante ressaltar que, ao contrário do que supõem alguns autores, o assim conhecido "voto econômico" também é relacionado com a competição e com o cálculo racional do eleitor. As avaliações do governo e dos partidos em disputa em termos de cálculo projetivo ou retrospectivo são fatores endógenos à competição eleitoral. Os fatores exógenos seriam as clivagens sociais, uma vez que a competição na arena eleitoral seria decorrência de uma disputa anterior e exterior às eleições. Há alguns autores (por exemplo, Amorim Neto and Cox, 1997) que vêm tentando articular os fatores endógenos e exógenos na explicação da fragmentação partidária, procurando defender a ideia de que o número de partidos é uma função de variáveis referentes tanto ao sistema eleitoral como à estrutura social.
} 
PERES, P. S. Institucionalização do sistema partidário ou evolução da competição?...

Mair (1990) e Mair (1997) analisaram a volatilidade eleitoral inter e intrablocos partidários, mostrando que a maioria dos eleitores oscilava seu voto entre partidos com proximidade ideológica e que, portanto, podiam ser agrupados em uma mesma família partidária. Desse modo, a volatilidade parecia ser decorrente do aumento da competição entre partidos do mesmo bloco ideológico e não de alguma incoerência por parte dos eleitores.

Sendo assim, a volatilidade poderia ser indicativa do grau e do padrão da disputa partidária, pois estaria relacionada com o número de partidos competitivos e com o grau de abertura do "mercado" eleitoral. Estaria relacionada também com o voto estratégico dos eleitores que, impedidos por qualquer motivo de votar nos partidos que ocupam a primeira posição de sua estrutura de preferências, decidiram destinar seus votos a outros partidos que estariam mais próximos daqueles. Na verdade, até mesmo a literatura que lida com o problema da coordenação eleitoral já traz implícita a hipótese de que a volatilidade é uma resposta racional dos eleitores ao portfólio de "oferta" partidária disponibilizado pelas elites políticas (por exemplo, Cox, 1997; Hug, 2001). Em termos empíricos, essa hipótese foi testada e confirmada por algumas pesquisas que analisaram o fenômeno nos países do Leste Europeu (BIRCH, 2000; TOOLE, 2000; Rose et al, 2001, ZIELINSKI, 2002; TWORZECKI, 2003, TAVITS, 2008b; BISCHOFF, 2012) e é uma conclusão possível para o caso brasileiro, a partir dos testes realizados por Peres, Ricci e Rennó (2011).

Sob tal ponto de vista, a explicação da instabilidade eleitoral ganha outro contorno analítico e outra interpretação teórica, deixando de ser fundamentada pela perspectiva estrutural-funcionalista para basear-se no individualismo metodológico. Com efeito, a cosmologia que the dá suporte axiomático concebe os indivíduos como atores orientados por uma racionalidade instrumental. Assim, considera-se que o eleitor toma decisões baseadas em uma estrutura de preferências políticas, obedecendo principalmente aos requisitos: de 1) ordenação, 2) coerência e 3) transitividade. As preferências dos eleitores seriam estruturadas porque seguiriam esses requisitos lógicos em qualquer situação de tomada de decisão. No que se refere aos partidos, os eleitores teriam determinadas preferências comparativas, por meio das quais classificariam mentalmente esses partidos em certa ordem de escolhas preferenciais $^{17}$.

Digamos, por exemplo, que um eleitor "E" prefira o partido "A" ao partido "B". Então, em qualquer decisão envolvendo a escolha entre esses dois partidos, e sem restrições exógenas, a preferência de "E" será sempre "A". Do mesmo modo, se houver um partido "C" e se o eleitor "E" preferir o partido "B" ao "C", toda vez que tal escolha se apresentar, também sem restrições exógenas, a

\footnotetext{
17 Grosso modo, podemos dizer que a preferência é um estado mental ou psicológico do indivíduo, enquanto a escolha é um ato concreto, um comportamento de tomada de posição diante de certas alternativas. A teoria microeconômica parte da pressuposição de que a escolha deve corresponder à preferência do indivíduo, ou seja, ao seu estado psicológico anterior ao ato da decisão efetiva. Suas predisposições o tornam suscetível para escolher certas alternativas em detrimento de outras, o que significa que o indivíduo possui uma estrutura de preferências dada ou prévia ao momento da decisão. Essa estrutura seria a ordenação de um conjunto de alternativas que, quando comparadas em pares são passíveis de avaliação qualitativa, ou seja, o indivíduo prefere, seja por qual motivo for, as qualidades de A em relação a B, por exemplo. Portanto, a preferência é algo essencialmente qualitativo. Porém, ela pode assumir valores quantitativos, de modo a ser possível estabelecer o quanto se prefere $A$ em relação a $B$, ou seja, o quanto o retorno esperado ou a utilidade de $A$ é maior que a de B. Em princípio, essa quantificação comparativa pode assumir valores que sejam maiores, menores ou equivalentes [>, <, ]. E, ainda, ao quantificar os graus de satisfação ou de utilidade de cada alternativa, seria possível que se estabelecessem os valores numéricos que permitiriam a ordenação quantitativa das preferências. Por isso, se, inicialmente, podemos dizer que preferimos $A$ a $B$, $B$ a $C$ e $A$ a $C$, em seguida, poderemos dizer que $A>B>C$. Já no caso de $A$ e $B$ serem equivalentes ou indiferentes, poderemos dizer que $A$ $\sim B>C$, ou seja, $A=B>C$.
} 
preferência será sempre favorável a "B". Sendo coerente, quando tiver que escolher entre "A" e "C", esse mesmo eleitor escolherá o partido "A". Além disso, quando não for possível ou mesmo estratégico escolher "A" - existência de restrições exógenas -, então, o eleitor "E" deverá decidir em favor de sua segunda melhor escolha, de acordo com sua estrutura de preferências, no caso, o partido "B"; e assim por diante, conforme a seguinte ordem de preferências estabelecida por graus quantitativos de utilidade de um partido em relação ao outro: $A>B>C^{18}$.

Seguindo esse exemplo, se entre duas eleições sucessivas houvesse uma mudança na votação do eleitor "E", que, no caso, teria escolhido o partido "A" na primeira eleição, e o partido "B" na segunda, e se isso ocorresse em função de qualquer tipo de restrição exógena à sua estrutura de preferências, cujo efeito tivesse sido o de impossibilitá-lo de manifestar sua preferência sincera pelo partido "A"19, estaríamos diante de algo perfeitamente coerente e até previsível. Assim, tanto a estabilidade - votações sucessivas no partido "A" -, como a instabilidade - votação em "A" e, depois, em "B" - seriam explicadas em termos racionais e poderiam ser interpretadas no contexto da competição eleitoral e da escolha estratégica dos eleitores vis-à-vis a maior ou menor coordenação das elites políticas, incentivadas pelo grau de restrições institucionais e os recursos à sua disposição.

Esse tipo de comportamento consiste precisamente na capacidade de tomada de decisões coerentes. Se "A" não é possível, então, "B", dado que "B" > "C"; e, acima de tudo, está relacionada com a distância quantitativa que agrupa os partidos em uma escala ordinal de preferências em um determinado espaço político. Tal distância refere-se às utilidades atribuídas a cada alternativa, representando sejam os valores cultivados pelo indivíduo, seja o montante de benefícios políticos que cada partido poderia Ihe trazer em relação ao seu mundo ideal de políticas públicas. Isso significa que a escolha do partido "B", quando "A" não é possível, não ocorre apenas porque o eleitor "E" prefere idealmente o partido "B" ao "C", mas porque, em termos espaciais - é importante ter em mente que o espaço, no caso, é político e representa bens e/ou valores -, o partido "B" está mais próximo de "A", ou seja, está mais próximo do pacote de benefícios políticos almejados por "E". Contrariamente, o partido "C" está mais distante do partido "A", portanto, suas políticas seriam mais distantes daquelas almejadas por esse eleitor.

Mesmo no caso de haver dois tipos de eleitores cujas preferências primeiras sejam ou o partido "A" (eleitor E) ou o partido "C" (eleitor E"), e que tenham em comum o partido "B" como segunda preferência, no caso de não poderem votar nos seus primeiros preferidos, deverão adotar a estratégia conjunta de votar no partido "B" - ou seja, coordenarão seus votos. Se houver ainda um terceiro tipo de

\footnotetext{
18 A preocupação com a tomada de decisão pela ótica da preferência pode ser encontrada já no século XIX, nos trabalhos de Georg Cantor, matemático alemão responsável pela proposição da teoria dos conjuntos. Mas, somente em meados dos anos 1920 ocorreria sua axiomatização mais rigorosa, pelo economista norueguês, Ragnar Frisch, um dos principais criadores da econometria e da distinção entre a micro e a macroeconomia. Nos anos 1950, essa teoria tornou-se ainda mais rigorosa em termos axiomáticos, por meio da contribuição de Gérard Debreu, um matemático e economista francês que formalizou de maneira mais definitiva a teoria do consumidor. Também houve contribuições importantes trazidas por teóricos mais críticos em relação à teoria do valor utilidade, como a de Arrow (1951), que levantaria o problema contido na agregação das preferências individuais (transitivas) em escolhas coletivas (intransitivas). Assim, apontou o paradoxo da racionalidade individual conduzir à irracionalidade nas decisões coletivas. Seguindo essa trilha, Buchanan and Tullock (1962) e Riker (1962, 1982) desenvolveriam a bastante influente teoria da escolha social. O destacado economista norte-americano, Paul Samuelson, nos anos 1940 e 1950, apontaria o problema relativo ao fato das preferências individuais, na verdade, serem fragilmente ordenadas. Em razão disso, esse autor acabaria propondo aquela que ficaria conhecida como a teoria das preferências reveladas.

${ }^{19}$ A restrição ao voto sincero no partido "A" poderia ser decorrente, por exemplo, da saída desse partido do processo competitivo - seja pela coordenação das elites partidárias ou pelo desaparecimento da legenda - ou de suas poucas chances de vitória diante dos partidos "B" e "C".
} 
eleitor ( $E$ '), cuja posição seja equidistante aos partidos "A" e "B", sua decisão terá um teor de indiferença perante os dois, pois ambos são equivalentes. A Figura 1 ilustra esses exemplos ( $E: A>B>C ; E^{\prime}: A \sim B$ $>$; E': $C>B>A$ ). Obviamente, diversas outras combinações poderiam ser supostas com a introdução de novos tipos de eleitores, de outros partidos ou simplesmente pelo deslocamento de cada uma dessas variáveis no espaço político.

Figura 1

Simulação da competição espacial dos hipotéticos partidos A, B e C

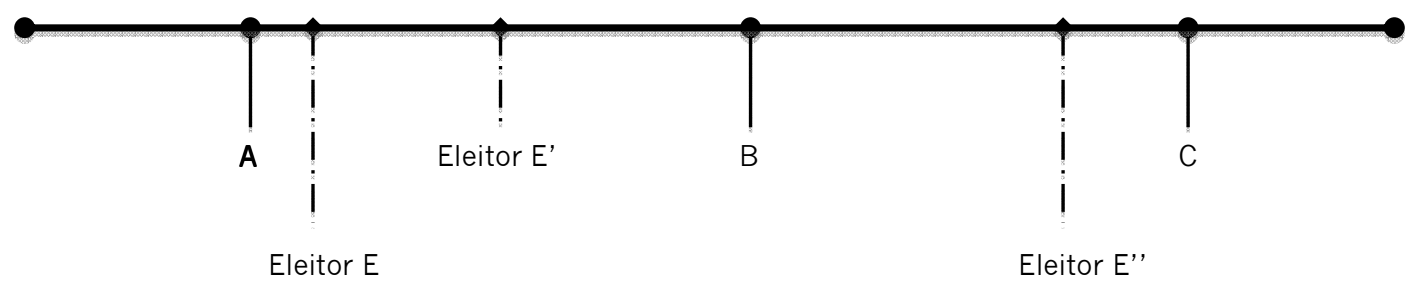

Estes casos hipotéticos mostram as possibilidades de mudança nas votações entre eleições sucessivas e a racionalidade das oscilações, que correspondem às decisões estratégicas dos eleitores diante de restrições exógenas à sua estrutura de preferências. A coexistência de vários partidos distribuídos no espaço político dinamiza ainda mais a competição, estimulando os votos estratégicos e, consequentemente, o aumento da volatilidade eleitoral. Esse efeito é provocado pela pequena distância entre os diversos partidos, o que, por extensão, diminui a distância ideológica que o eleitor tem de percorrer para mudar seu voto, diminuindo também os custos da mudança até um limite em que seu ganho marginal será menor do que seu custo marginal ${ }^{20}$. Sob essa ótica, o elemento estratégico da escolha é o responsável pelas oscilações estruturalmente coerentes nas votações.

Contudo, tais exemplos representam um modelo estático de sistema partidário, em que o "mercado" eleitoral está fechado, sem "entrada" e "saída" de competidores. Em situações reais, ocorre esse fluxo de "entradas" e "saídas" de partidos, funcionando como um estímulo ainda mais poderoso à volatilidade eleitoral, pois provoca alterações no padrão da competição - embora não necessariamente implique em aumento da competitividade partidária, uma vez que competição e competitividade são coisas diferentes. Num mercado competitivo, a interação é dinâmica e as demandas e ofertas são mais elásticas. Assim, além de determinados incentivos ou restrições institucionais, vinculados ao sistema eleitoral (fórmula eleitoral, princípio de representação, magnitude do distrito, etc.), o número de partidos em competição e a distribuição das preferências eleitorais agregadas em torno desses partidos surgem

\footnotetext{
20 Há, portanto, uma elasticidade no deslocamento do eleitor e dos partidos no eixo ideológico. Mas, o deslocamento na margem dessa elasticidade será tão mais frequente e menos custoso quanto maior for o número de partidos nesse intervalo. O deslocamento também não é pleno, pois, quanto mais próximo do limite da elasticidade, maior o custo marginal e menor o ganho marginal do deslocamento. Outro detalhe que deve ser observado refere-se a possíveis análises de correlação entre o número efetivo de partidos e a volatilidade eleitoral, como forma de testar se, de fato, sistemas multipartidários fragmentados tendem a ser mais voláteis. Ocorre que, não necessariamente, haverá tal correlação, mas isso não invalida o argumento, pois o teste não é apropriado para a detecção desse efeito. Desconsiderando-se os problemas já reconhecidos das mensurações do número efetivo de partidos, o que está em questão não é a variação desse número, mas sim a distância ideológica entre os partidos do sistema e as restrições e oscilações do mercado em termos da oferta partidária e seus impactos sobre as preferências eleitorais.
} 
como variáveis intervenientes preponderantes no cálculo que os eleitores terão de fazer no momento da decisão do voto coordenado ${ }^{21}$.

Essa mudança de enfoque, portanto, parte da concepção de que a volatilidade eleitoral pode estar associada à lógica da competição partidária num ambiente ecológico, em função de fatores relacionados com os movimentos do "mercado político" - "oferta/demanda" e "restrições" (regras e recursos). As regras têm um peso importante na relação "oferta/demanda" e podem também interferir nos "recursos". Por exemplo, em países com regras eleitorais mais inclusivas, ou seja, aqueles que adotam fórmulas de representação proporcional, com distritos de elevada magnitude, e assim por diante, a "livre-concorrência" entre os partidos é máxima. Em contextos bastante abertos à competição, como o brasileiro, adota-se, inclusive, a votação em listas abertas, de modo que, além da formação de um sistema multipartidário consideravelmente fragmentado, promove-se a disputa entre candidatos do mesmo partido, provocando diversos efeitos seja na "oferta" partidária, seja na "demanda" eleitoral ${ }^{22}$.

O Esquema 1 sintetiza essa perspectiva heurística. Analogamente, assim como na dinâmica do mercado econômico, quaisquer alterações no "mercado político", como entradas, saídas, cisões e fusões de partidos, produzem determinados rearranjos na estrutura de preferências dos eleitores. Se um partido sai do "mercado eleitoral", seus eleitores são obrigados ou 1) a deixar de participar das eleições ou 2) a escolher outro partido disponível e que tenha um perfil programático próximo daquele; e o mesmo vale para parlamentares que decidem não concorrer à reeleição. Se um novo partido entra no "mercado eleitoral", ele pode vir a ocupar uma posição política que esteja mais próxima do ponto ideal de um conjunto de eleitores que até então votavam em um partido que se localiza um pouco mais distante desse ponto. Com isso, os eleitores poderão se sentir estimulados a mudar seu voto na eleição seguinte; mas, é claro, levando em consideração a viabilidade eleitoral desse novo partido. Processos semelhantes também poderiam ocorrer com fusões e cisões partidárias, dado que, na prática, esses processos funcionam como "entrada" e "saída" de partidos no "mercado eleitoral"23.

\footnotetext{
21 É importante observar que, conforme mostraram algumas pesquisas, também pode ocorrer voto estratégico em sistemas eleitorais proporcionais (COX, 1997; CoX and SHUGART, 1996; LAGO, 2008; SHIKANO et al, 2009) e em sistemas eleitorais mistos (KRISEI, 1998; REED, 1999; KARP et al, 2002; Moser \& ScheINER, 2009). Para uma discussão mais detalhada sobre as modalidades de voto estratégico, ver Bischoff (2011).

22 Analisando diversos países da Europa industrializada, Bischoff (2011) encontrou uma correlação significativa entre o voto estratégico, o número de partidos e a volatilidade eleitoral, concluindo que as variáveis institucionais seriam mais determinantes para explicar o fenômeno do que as variáveis sociológicas tradicionais. No caso do Brasil, dados apresentados por Peres, Ricci e Rennó (2011) mostram que também há correlação significativa entre a volatilidade eleitoral no país e as decisões das lideranças políticas de criar novos partidos, de fundir dois ou mais partidos, de concorrer ou não à reeleição e de trocar de partido durante o mandato parlamentar. Seus dados permitem inferir que a volatilidade eleitoral brasileira pode ser explicada pela combinação dos seguintes fatores: 1) o voto estratégico (coordenação eleitoral, restrições institucionais), 2) voto sincero (migração de parlamentares entre os partidos) e 3) movimentos de mercado (entradas e saídas de partidos, incluindo-se as fusões e cisões).

23 Outro aspecto a ser considerado no caso brasileiro envolve as constantes mudanças na legislação eleitoral, desde as mais reduzidas até as mais abrangentes, seja por novas normatizações ou por interpretações de regras já existentes. Um exemplo claro disso ocorreu em 2007, quando o TSE entendeu que o mandato pertence ao partido, e não ao representante eleito, e que, portanto, ao deixar seu partido, o parlamentar perderia seu mandato. Ao abrir a exceção da nulidade da perda do mandato para casos em que o representante venha a se filiar a uma legenda recém-criada, deu-se, não obstante, vigoroso incentivo à criação de novos partidos, como ilustra o caso do PSD e de inúmeros outros partidos que atualmente buscam cumprir os requisitos formais para a obtenção do registro junto ao TSE. Isso provoca dois efeitos na "oferta" partidária: 1) aumenta o número de partidos e 2) leva políticos com eleitores fiéis a migrarem para essas novas legendas. Essa oscilação na "oferta" pode ter impacto na "demanda" tanto no que se refere ao voto sincero como no que se refere ao voto estratégico. Em um caso ou no outro, é esperado que essa evolução tenha impacto final na volatilidade eleitoral.
} 


\section{Esquema 1 \\ Modelo heurístico dos elementos interativos \\ do mercado político na produção da volatilidade eleitoral}

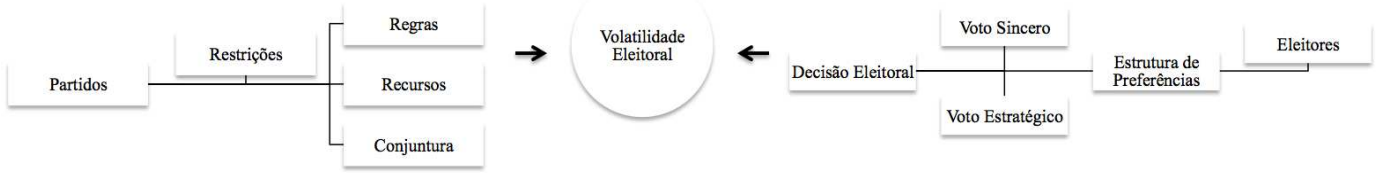

Desse modo, a consequência mais imediata dessa concepção é a suposição de que quanto mais "aberto" o "mercado" eleitoral, maiores os movimentos de "oferta/demanda" e o grau de competição partidária, dando oportunidade à manifestação de maior volatilidade nas votações. Entretanto, tal volatilidade não significaria uma ruptura das identidades políticas; muito menos os sinais iniciais de uma crise institucional generalizada, e sim a evidência de um comportamento estratégico dos eleitores.

Obviamente, alguém poderia argumentar que tal perspectiva incorreria no mesmo problema do paradigma sociológico, porém, com o sinal trocado: ou seja, enquanto o viés sociológico valoriza a estabilidade como indicador de racionalidade institucional e do eleitor, o paradigma IR (Institucional Racionalista) valoriza a instabilidade como indicador de tal racionalidade. Pode-se argumentar, então, que, no limite, para a perspectiva IR, quanto mais instável o eleitor, mais racional sua decisão, na medida em que a instabilidade seria evidência de seu cálculo eleitoral. Contudo, tal raciocínio não é verdadeiro. Em primeiro lugar porque, mesmo no caso do cálculo do diferencial partidário, o eleitor pode decidir votar no mesmo partido, dado que este pode lhe trazer mais benefícios do que os concorrentes. Em segundo lugar, porque, apesar da possibilidade racional e estratégica de ser volátil em decorrência do problema da incerteza e da carência informacional que caracteriza o "mercado" imperfeito da política, a ideologia surge como um atalho no caminho da coleta de informações relevantes para a escolha eleitoral, de modo que sejam supridas as informações mínimas para que os eleitores tomem suas decisões e não sejam indiferentes em relação aos competidores (Downs, 1957). Em outras palavras, a ideologia representa, acima de tudo, um abatimento nos custos de informação para o eleitor e uma sinalização racional que o partido emite para que possa gerar a certeza agregada a respeito de suas ações futuras. Sendo assim, esse modelo interpretativo também atribui racionalidade à estabilidade eleitoral, relacionando-a ao problema da incerteza informacional e à dinâmica da competição espacial.

Então, se concentrarmos a análise especificamente nos aspectos dinâmicos da competição, a volatilidade eleitoral indica o nível das oscilações agregadas, ou seja, o grau de competição e de abertura do "mercado político"; indica em que ponto concentra-se a competição, em que ponto o mercado é mais segmentado, quais partidos dominam o "mercado eleitoral" em que segmentos e espaços geográficos. Consequentemente, as preocupações analíticas podem ser voltadas então a questões como estas, por exemplo: que tipo de preferências são estruturadas? Qual é a estrutura da escolha eleitoral em termos de "ofertas" partidárias? Que padrão seguem as oscilações? Elas são crescentes ou declinantes? As 
oscilações devem-se mais ao fluxo de votos entre os partidos indiscriminadamente ou entre blocos partidários específicos? Que partidos competem uns com os outros em cada bloco partidário e que partidos lideram as votações nos mesmos blocos? As oscilações se devem às alterações na "oferta", na "demanda" ou nas "restrições" (regras e recursos)? Em que medida alterações nas "restrições" alteram a relação "oferta/demanda" e, com isso, a volatilidade eleitoral?

Indubitavelmente, essa é uma perspectiva que pode trazer grandes contribuições analíticas ao estudo dinâmico dos sistemas partidários e à interpretação da volatilidade eleitoral ${ }^{24}$. A ênfase explicativa não privilegia qualquer viés normativo favorável seja à instabilidade ou à estabilidade, mas apenas a explicação contextualizada da evolução das votações e das oscilações encontradas mediante certos movimentos do "mercado eleitoral". No escopo dessa heurística institucional-racionalista, admitese apenas isto: a estabilidade e a instabilidade são igualmente esperadas e racionais, sendo impossível, portanto, determinar a priori um ponto ótimo para a volatilidade eleitoral, uma vez que as oscilações dependem de fatores históricos, conjunturais e institucionais que, em cada momento, induzem os atores à determinada escolha, à determinada transitividade em sua estrutura de preferências e, dessa maneira, a determinado comportamento estratégico.

\section{Considerações Finais}

Meu principal objetivo neste artigo foi justificar a proposição de uma interpretação econômica para o índice de volatilidade eleitoral, em substituição à convencional teoria sociológica desenvolvimentista. Conforme discutido, a proposição do vínculo entre a volatilidade eleitoral e a instabilidade do sistema partidário é lógica e teoricamente frágil, assim como é contestável atribuir-Ihe um significado de crise iminente do sistema representativo. Essa cadeia causal carece, inclusive, de base empírica, afinal, se a instabilidade é concebida como sinal de crise sistêmica e se não há evidências que corroboram tal assertiva, logo, esta não necessariamente significa crise institucional. Sendo assim, tudo indica que a crise não é dos sistemas partidários, mas do paradigma explicativo convencional, que dá mostras de incontornáveis anomalias lógicas e empíricas.

A partir disso, procurei defender que é mais adequado estabelecer um vínculo entre a volatilidade eleitoral e os movimentos do "mercado político", envolvendo a relação entre a "oferta" partidária e a "demanda" de eleitores estratégicos diante de "incentivos" institucionais e dos recursos disponíveis. Todos esses elementos são centrais no paradigma institucional-racionalista, o qual não estabelece, de partida, qualquer posição normativa acerca de possíveis valores ótimos para o índice, nem faz juízos a priori acerca de qualquer sinal de crise institucional com base naqueles valores. Pelo contrário, cada valor observado em cada país, em cada sistema partidário específico deve ser

\footnotetext{
24 Inclusive, essa perspectiva parece ser mais eficiente para explicar o próprio caso brasileiro, que sempre deixa grandes arestas fora do esquadro das interpretações sociológicas usuais. Afinal, em virtude da extensão territorial e das diversidades regionais, a especificidade do nosso sistema partidário deve ser levada em consideração no que se refere tanto às dinâmicas particulares de cada estado como à formação histórica da configuração atual. Durante o regime autoritário, embora controlado e restringido, o sistema partidário continuou em operação e, além disso, foi parte integrante da estratégia de abertura política adotada no modelo de transição pactuada e gradual, desenhada com claros incentivos à fragmentação da oposição ao governo nos primeiros anos da transição democrática. Então, sua evolução deve ser entendida como um desdobramento do sistema anterior e não como uma ruptura radical em relação ao mesmo. A volatilidade eleitoral pode ser apreendida, então, como um dos elementos componentes do processo de abertura do mercado político à competição mais concorrencial e livre, com a configuração do multipartidarismo em oposição ao duopólio do bipartidarismo compulsório do período anterior.
} 
interpretado de maneira circunscrita, pois cada nível de instabilidade eleitoral pode significar coisas bastante diferentes em cada contexto.

Certo nível de volatilidade no Reino Unido pode significar algo diferente do mesmo nível encontrado no Brasil, por exemplo, assim como volatilidades diferentes em países diferentes, em certas circunstâncias, podem ter significados semelhantes. Em alguns casos, a volatilidade eleitoral pode estar associada a alterações na "demanda"; em outros, a alterações na "oferta". Em outros, ainda, pode estar associada, em graus variados, a ambas as coisas. Por sua vez, alterações na "demanda" podem ser explicadas em função de variáveis sociais, econômicas e culturais, enquanto alterações na "oferta" podem ser explicadas em função de variáveis políticas, como o aumento ou a redução nas restrições à livre competição. E outras vezes, também, as alterações na volatilidade eleitoral podem ser explicadas em função da volatilidade das elites políticas - problemas de coordenação, migração entre partidos, desistência da candidatura, etc.

Portanto, a interpretação canônica da instabilidade eleitoral como indicador de institucionalização do sistema partidário nos induz a perceber apenas sinais de crise em processos que podem, pelo contrário, representar justamente o oposto, ou seja, a estruturação mais efetiva de um "mercado" político-eleitoral pouco restritivo e, portanto, altamente competitivo. A instabilidade eleitoral observada na Europa nos últimos anos e em diversos países de democracia recente pode ser a indicação de democracias mais competitivas, nas quais os atores tomam decisões baseadas em preferências estruturadas de uma determinada forma e que têm que fazer escolhas em um "mercado político" mais aberto e concorrencial. Mas pode também significar o descontentamento dos eleitores em relação às "ofertas" partidárias e às políticas públicas; pode significar até mesmo alguma "crise" do "mercado eleitoral" em virtude da regulação excessiva ou permissiva, de algum desequilíbrio entre a "oferta" e a "demanda". Pode, na verdade, significar várias coisas e não apenas uma, como suposto pelo paradigma sociológico-desenvolvimentista. Mas, todos esses significados somente poderão ser apreendidos de forma mais eficiente teórica, metodológica e epistemologicamente com uma abordagem contextualizada sob a perspectiva institucional-racionalista.

\section{Referências Bibliográficas}

ALDRICH, J. Why Parties? The Origin and Transformation of Political Parties in America. Chicago: Chicago University Press, 1995.

Amorim Neto, O. \& Cox, G. "Electoral Institutions, Cleavage Structures and the Number of the Parties". American Journal of Political Science, vol. $41, n^{\circ} 1,1997$.

Aristóteles. A Política. São Paulo: Martins Fontes, 1999.

ARrow, K. Social Choice and Individual Values. New Haven: Yale University Press, 1951.

BARTOLINI, S. \& MAIR, P. Identity, Competition, and Electoral Availability: The Stabilization of European Electorates (1885-1985). Cambridge: Cambridge University Press, 1990.

Bengtsson, A. "Economic Voting: The Effect of Political Context, Volatility and Turnout on Voters' Assignment of Responsibility". European Journal of Political Research, vol. 43, n 5, p. 749-767, 2004.

BIELASIAK, J. "Substance and Process in the Development of Party Systems in East Central Europe". Communist and Post-Communist Studies, vol. 30, n 1, p. 23-44, 1997. 
"The Institutionalization of Electoral and Party Systems in Post-Communist States". Comparative Politics, vol. 34, n² 2, p. 189-210, 2002.

BIRCH, S. Elections and Democratization in Ukraine. Basingstoke: Macmillan, 2000.

2003.

Electoral Systems and Political Transformation in Post-Communist Europe. New York: Palgrave Macmillan,

BISChOFF, C. "Electorally Unstable by Supply or Demand? An Examination of the Causes of Electoral Volatility in Advanced Industrial Democracies". Public Choice, Published On-Line, 2011. Acesso: 05 jan. 2012.

Bottomore, T. B. Elites and Society. London: C. A. Watts and Co., 1964.

Buchanan, J. \& Tullock, G. The Calculus of Consent. Ann Arbor: University of Michigan Press, 1962.

Budge, I. \& Kelman, H. Parties and Democracy: Coalition Formation and Government Functioning in Twenty States. Oxford: Oxford University Press, 1993.

BUTLER, D. The Study of Political Behavior. London: Routledge, 1958.

Charlesworth, J. The Limits of Behavioralism in Political Science. Philadelphia, 1962.

Coppedge, M. “The Dynamic Diversity of Latin American Party Systems”. Party Politics, vol. 4, n 4, p. 547-568, 1998.

Cortona, P. G. di; Manzi, C.; Peennisı, A.; RiccA, F. and Simeone, B. Evaluation and Optimization of Electoral Systems. Philadelphia: SIAM, 1999.

Cox, G. Making Votes Count: Strategic Coordination in the World's Electoral Systems. Cambridge: Cambridge University Press, 1997.

\& SHUGART, M. "Strategic Voting under Proportional Representation". Journal of Law, Economics and Organization, vol. 12, n², p. 299-324, 1996.

Cunningham, F. Theories of Democracy: A Critical Introduction. London: Routledge, 2002.

CREWE, I. Introduction: Electoral Change in Western Democracies: A Framework for Analysis. In: CREWE, I. \& DENVER, D. (eds.). Electoral Change in Western Democracies. London: Croom Helm, 1985.

\& Denver, D. (eds.). Electoral Change in Western Democracies. London: Croom Helm., 1985.

DAHL, R. A Preface to Democratic Theory. Chicago: The University of Chicago Press, 1956.

"The Behavioral Approach". American Political Science Review, vol. 55, n4, 1961.

Polyarchy: Participation and Opposition. New Haven: Yale University Press, 1971.

How Democratic is the American Constitution? New Haven: Yale University Press, 2003.

Dalton, R.J.; Flanagan, S.C. and BeCk, P.A. (eds.). Electoral Change in Advanced Industrial Democracies. Realignment or Dealignment? Princeton: Princeton University Press, 1984.

Downs, A. An Economic Theory of Democracy. New York: Harper and Row, 1957.

Duverger, M. Les Partis Politiques. Paris: Librairie Armand Colin, 1951.

EASTON, D. The Current Meaning of 'Behavioralism' in Political Science. In: CHARLESWORTH, J. (Ed.). The Limits Behavioralism in Political Science. Philadelphia: The American Academy of Political and Social Science, 1962.

ELKINS, D. "The Measurement of Party Competition. The American Political Science Review, 68, p. 682-700, 1974.

Eulau, H.; Eldersveld, S. and Janowitz, M. (eds.). Political Behavior. A Reader in Theory and Research. Illinois: Glencoe, 1956.

The Behavioral Persuasion. New York: The Free Press, 1963.

Evans, J. "In Defence of Sartori: Party System Change, Voter Preference Distribution and other Competitive Incentives". Party Politics, vol. 8, n², p. 155-174, 2002. 
PERES, P. S. Institucionalização do sistema partidário ou evolução da competição?...

Gallagher, M. "Proportionality, Disproportionality and Electoral Systems". Electoral Studies, 10, p. 33-51, 1991.

Haggard, S. \& Kaufmann, R. The Political Economy of Democratic Transitions. Princeton: Princeton University Press, 1995.

Hall, P. \& TAYLoR, R. "Political Science and the Three New Institutionalisms". Political Studies, vol. 44, n 5, p. 936-957, 1996.

Hamilton, A.; MAdison, J. \& JaY, J. The Federalist. Chicago: University of Chicago/Britannica, 1952.

HELD, D. Models of Democracy. Cambridge: Polity Press, 1987.

HuG, S. Altering Party Systems. Ann Arbor: University of Michigan Press, 2001.

Huntington, S. Political Order in Changing Societies. New Haven: Yale University Press, 1968.

KarP, J.; Vowles, J.; Banduccl, S. and Donovan, T. "Strategic Voting, Party Activity, and Candidate Effects: Testing Explanations for Split Voting in New Zealand's new Mixed System”. Electoral Studies, vol. 21, n 1, p. 1-22, 2002.

Kato, J. "Institutions and Rationality in Politics: Varieties of Neo-Institutionalists". British Journal of Political Science, vol. $26, \mathrm{n}^{\circ} 4,1996$.

Katz, R. \& MaIR, P. How Parties Organize: Change and Adaptation in Party Organizations in Western Democracies. London: Sage Publications, 1994.

"Changing Models of Party Organization and Party Democracy". Party Politics, vol. 1, n 1, p. 5.28, 1995.

"Cadre, Catch-All or Cartel? A Rejoinder". Party Politics, vol. 02, n 4, p. 525-534, 1996.

KeLSEN, H. A Democracia. São Paulo: Martins Fontes, 1993.

KIRCHHEIMER, O. The Transformation of the Western European Party Systems. In: LAPALOMBARA, J. and WeineR, M (eds.). Political Parties and Political Development. Princeton: Princeton University Press, 1966.

"A transformação dos sistemas partidários da Europa Ocidental". Revista Brasileira de Ciência Política, vol. 7, p. $349 \cdot 385,2012$

KITSCHELt, H. The Transformation of European Social Democracy. New York: Cambridge University Press, 1994.

.; Manssfeldova, Z. \& Markowski, R. Post-Communist Party Systems: Competition, Representation and Inter Party Cooperation. Cambridge: Cambridge University Press, 1999.

Kreuzer, M. \& Pettal, V. "Patterns of Political Instability: Affiliation Patterns of Politicians and Voters in Post-Communist Estonia, Latvia and Lithuania". Studies in Comparative International Development, vol. 38, n², p. 76-98, 2003.

"Political Parties and the Study of Political Development: New Insights from the Post-Communist Democracies". World Politics, 56, p. 608-633, 2004.

KRISEI, H. "Straightforward and Strategic Voting in the Elections for the Swiss Council of States in 1995". Electoral Studies, vol. 17, $\mathrm{n}^{\circ} 1$, p. 45-59, 1998.

KuenzI, M. \& Mabright, G. "Party Systems Institutionalization in 30 African Countries". Party Politics, vol. 7, n 4 , p.437. $468,2001$.

LAGO, I. "Rational Expectations or Heuristics? Strategic Voting in Proportional Representation Systems". Party Politics, vol. 14, n 1, p. 31-49, 2008.

LANE, J. E. \& ERSSON, S. "Parties and Voters: What Creates the Ties?". Scandinavian Political Studies, vol. 20, n², p. $179-196,1997$.

Laver, M. \& Benoit, K. "The Evolution of Party Systems Between Elections". American Journal of Political Science, vol. $47, n^{\circ} 2$, p. $215-233,2003$

Lewis-Beck, M. \& Stegmaler, M. "Economic Determinants of Electoral Outcomes". Annual Review of Political Science, 3, p. 183-219, 2000.

LIJPHART, A. "Consociational Democracy". World Politics, 21, p. 207-25, 1969. 
OPINIÃO PÚBLICA, Campinas, vol. 19, no 1, junho, 2013, p. 21-48

. Democracy in Plural Societies: A Comparative Exploitation. New Haven: Yale University Press, 1977.

. Democracies: Patterns of Majoritarian and Consensus Government in Twenty-One Countries. New Haven: Yale University Press, 1984

Electoral Systems and Party Systems: A Study of Twenty-Seven Democracies (1945-1990). Oxford: Oxford University Press, 1994

Patterns of Democracy: Government Forms and Performance in Thirty-Six Countries. New Haven: Yale University Press, 1999

LIPSET, M. \& RokKAN, S. Cleavage Structures, Party Systems, and Voter Alignments: an Introduction. In: LIPSET, M. \& Rokkan, S. (eds.). Party Systems and Voter Alignments: Cross National Perspectives. New York: The Free Press, 1967.

LOCKE, J. The Second Treatise of Government. New York: Hackett, 1980.

LoOSEmORE, J. \& HAnBy, V. "The Theoretical Limits of Maximum Distortion: Some Analytical Expressions for Electoral Systems". British Journal of Political Science, 01, p. 467.477, 1971.

MacPherson, C. B. The Life and Times of Liberal Democracy. Oxford: Oxford University Press, 1977.

MAGUIRE, M. Is there still Persistence? Electoral Change in Western Europe, 1948-1979. In: DaALDER, H. \& MaIR, P. (eds.). Western European Party Systems: Continuity and Change. London: Sage, 1983.

MaInWARING, S. Brazil: Weak Parties, Feckless Democracy?. In: MaInWARING, S. and Scully, T. (eds.). Building Democratic Institutions: Parties and Party Systems in Latin America. Stanford: Stanford University Press, 1995.

"Rethinking Party System Theory in the Third Wave of Democratization: The Importance of Party System Institutionalization". Working Paper 260, Helen Kellogg Institute for International Studies, University of Notre Dame, 1998a.

"Electoral Volatility in Brazil", Party Politics, 4, p. 523-545, 1998b.

"Party Systems in the Third Wave". Journal of Democracy, 9, p. 67-81, 1998c.

University Press, 1999.

"Introduction". In: , and SCuLly, T. (eds.). Building Democratic Institutions: Party Systems in Latin America. Stanford: Stanford University Press, 1995.

\& SCULly, T. A Institucionalização dos Sistemas Partidários na América Latina”, Dados, 37/1, 1994.

\& TORCAL, M. Party System Institutionalization and Party System Theory after the Third Wave of

Democratization. In: KATZ, R. \& CROTTY, W. (eds.). Handbook of Party Politics. London: Sage Publications, 2006.

\& Zoco, E. "Political Sequences and the Stabilization of Interparty Competition: Electoral Volatility in Old and New Democracies", Party Politics, vol. 13, n², p. 155. 178, 2007

MAIR, P. Party System Change: Approaches and Interpretations. Oxford: Oxford University Press, 1997.

"Os Partidos e a Democracia". Análise Social, 38/167, p. 277-293, 2003.

Manin B. The Principles of Representative Government. Cambridge: Cambridge University Press, 1997.

MAOR, M. Political Parties and Party Systems: Comparative Approaches and the British Experience. London: Routledge, 1997.

MARCH, J. \& OlSEN, J. "The New Institutionalism: Organizational Factors in Political Life". The American Political Science Review, vol. 78, $\mathrm{n}^{\circ} 3,1984$.

MatTILA, M. \& RaUniO, T. "Does Winning Pay? Electoral Success and Government Formation in 15 West European Countries". European Journal of Political Research, 43, p. 263-285, 2004.

MILL, J. S. Representative Government. Chicago: University of Chicago/Britannica, 1952.

MonRoE, B. L. "Disproportionality and Malapportionment: Measuring Electoral Inequity". Electoral Studies, 13, p.132.49, 1994. 
PERES, P. S. Institucionalização do sistema partidário ou evolução da competição?...

Moser, R. \& SCHEINER, E. "Strategic Voting in Established and New Democracies: Ticket Splitting in Mixed-Member Electoral Systems", Electoral Studies, vol. 28, n 1, p. 51-61, 2009.

Montesquieu, C. de De L'Esprit des Lois. In: Oeurres Completes de Montesquieu. Paris: Gallimard, 1949.

Mozaffar, S. \& ScarritT, J. "The Puzzle of African Party Systems”. Party Politics, vol. 11, n 4, p. 399-421, 2005.

Müller, W. \& StrØM, K. Policy, Office or Votes? How Political Parties in Western Europe Make Hard Decisions. New York: Cambridge University Press, 1999.

NoORGaARD, S. "Rediscovering Reasonable Rationality in Institutional Analysis". European Journal of Political Research, 29, 1996

OLSON, D. "Party Formation and Party System Consolidation in the New Democracies of Central Europe". Political Studies, 46, p. 432-464, 1998.

Panebianco, A. Modelli di Partito: Organizzazione e Potere nei Partitti Politici. Bolonha: II Mulino, 1982.

Pedersen, M. "The Dynamics of European Party System: Changing Patterns of Electoral Volatility". European Journal of Political Research, vol. $7, \mathrm{n}^{\circ} 1,1979$.

"On Measuring Party System Change: A Methodological Critique and a Sugestion". Comparative Political Studies, vol. 12, $\mathrm{n}^{\circ} 4,1980$.

Pennings, P. The Triad of Party System Change: Votes, Office and Policy. In: Pennings, P. and Lane, J. E. (eds.). Comparing Party System Change. London: Routledge, 1998.

PENNISI, A. "Disproportionality Indexes and Robustness of Proportional Allocation Methods". Electoral Studies, 17, p. 3-19, 1998.

Peres, P. "Comportamento ou Instituições? A Evolução Histórica do Neo-Institucionalismo da Ciência Política". Revista Brasileira de Ciências Sociais, 68/23, p. 53.72, 2008.

. "As Abordagens Neo-Institucionais da Política: Uma Proposta Alternativa de Análise Classificatória". Revista Versões, 03/04, p. 145.178, 2007.

. "O Problema da Instabilidade Eleitoral na Europa: Uma Análise do Debate Teórico, Empírico e Metodológico". Boletim Informativo Bibliográfico de Ciências Sociais - BIB, 60, p. 87.118, 2005.

.; RıcCI, P. e RenNó, L. "A Variação da Volatilidade Eleitoral no Brasil: Um Teste das Explicações Políticas, Econômicas e Sociais". Latin American Research Review, vol. 46, n³, p. 46.68, 2011.

PoweLL, B.G. "Party Systems and Political System Performance: Voting Participation, Government Stability and Mass Violence in Contemporary Democracies". The American Political Science Review, 75, p. 861-879, 1981.

1982

Contemporary Democracies: Participation, Stability and Violence. Cambridge: Harvard University Press.

PridDham, G. Securing Democracy: Political Parties and Democratic Consolidation in Southern Europe. London/New York: Routledge, 1990.

PrzeWorski, A. "Institutionalization of Voting Patterns, or is Mobilization the Source of Decay?". American Political Science Review, vol. 69, n 1, p. 49-67, 1975.

RAE, D. W. The Political Consequences of Electoral Laws. New Haven: Yale University Press, 1967.

RANney, A. Essays on the Behavioral Study of Politics. Illinois: Urbana, 1962.

REICH, G. "The Evolution of New Party Systems: Are Early Elections Exceptional?". Electoral Studies, 23, p. 235-250, 2004.

ReED, S. "Strategic Voting in the 1996 Japanese General Election". Comparative Political Studies, vol. 32, n², p.257. 270, 1999.

Remmer, K. "The Political Impact of Economic Crisis in Latin America in the 1980s". The American Political Science Review, vol. 85, n³, p. 777-800, 1991. 
RIKER, W. The Theory of Political Coalitions. New Haven: Yale University Press, 1962.

Liberalism against Populism: A Confrontation between the Theory of Democracy and the Theory of Social Choice. Prospect Heights: Waveland Press, 1982.

Roberts, K. \& Wibbels, E. "Party Systems and Electoral Volatility in Latin America: A test of Economic, Institutional and Structural Explanations". American Political Science Review, vol. 93, n 3, p. 575-590, 1999.

Rose, R. \& URwin, D. "Persistence and Change in Western Party Systems since 1945". Political Studies, vol. 18, n 3, p. 287-319, 1970.

Rose, R.; MunRo, N. and WHITE, S. "Voting in a Floating Party System: The 1999 Duma Election", Europe-Asia Studies, 53/03, p. 419.443, 2001.

Shamir, M. Are Western European Party Systems Frozen?", Comparative Political Studies, vol. 17, n 1, p. 35-79, 1984.

SIKK, A. "How Unstable? Volatility and the Genuinely New Parties in Eastern Europe", European Journal of Political Research, 44, p. 391-412, 2005.

Shikano, S.; HeRrmann, M. \& Thurner, P. "Strategic Voting under Proportional Representation: Threshold Insurance in German Elections", West European Politics, vol. 32, n 3, p. 634-656, 2009.

StRØм, K. "Party goals and Government Performance in Parliamentary Democracies". The American Political Science Review, vol. 79, n³, p. 738-754, 1985.

1990.

"A Behavioral Theory of Competitive Political Parties". American Journal of Political Science, vol. 34, n 1 ,

“Democracy as Political Competition". American Behavioral Scientist, 35/4-5, p. 375-396, 1992.

TaAgepera, R. Making Social Sciences more Scientific: The Need for Predictive Models. Oxford: Oxford University Press, 2008.

\& GROFMAN, B. "Mapping the Indices of Seats-Votes Disproportionality and Inter-Election Volatility". Party Politics, vol. 9, n 6, p. 659-677, 2003.

TAVITS, M. "The Development of Stable Party Support: Electoral Dynamics in Post-Communist Europe". American Journal of Political Science, vol. 49, n² 2, p. 283-298, 2005.

"Party Systems in the Making: The Emergence and Success of New Parties in New Democracies". British Journal of Political Science, vol. 38, n 1, p. 113-134, 2008a.

"On the Linkage Between Electoral Volatility and Party System Instability in Central and Eastern Europe". European Journal of Political Research, 47, p. 537.555, 2008b.

TocQueville, A. De la Démocratie en Amérique. Paris: GF.Flammarion, 1991.

TOKA, G. Parties and Electoral Choices in East-Central Europe. In: PRIDHAM, G. \& LeWIS, P. (eds.). Stabilising Fragile Democracies: Comparing New Party Systems in Southern and Eastern Europe. London: Routledge, 1995.

"Party Appeals and Voter Loyalty in New Democracies". Politica/Studies, vol. 46, n³, p. 589-610, 1998.

TOOLE, J. "Government Formation and Party System Stabilization in East Central Europe". Party Politics, vol. 6, n 4, p. 441-461, 2000.

TworzeCKI, H. Learning to Choose: Electoral Politics in East-Central Europe. Stanford: Stanford University Press, 2003.

ZIELINSKI, J. "Translating Social Cleavages into Party Systems: The Significance of New Democracies". World Politics, 54, p. 184-211, 2002.

Paulo Sergio Peres · peres.ps@gmail.com

Submetido à publicação em fevereiro de 2012. Aprovado para publicação em abril de 2012. 